\title{
Trade, Reform, and Structural Transformation in South Korea ${ }^{\mathrm{a}}$
}

\author{
Caroline Betts ${ }^{\mathrm{b}}$ \\ USC
Rahul Giric
ITAM \\ Rubina Verma ${ }^{\mathrm{d}}$ \\ ITAM
}

First Version: Feb 2011, This Version: January 2017

\begin{abstract}
We develop a quantitative two country, three-sector model to measure the effects of trade policies for Korean structural change from 1963 through 2000. The model features non-homothetic preferences, Armington trade, proportional import tariffs and export subsidies, and is carefully calibrated to match sectoral value added production and value added trade between Korea and the OECD. We find that tariff liberalization increased imports and total trade, especially agricultural imports, accelerating de-agriculturization and intensifying Korean industrialization. Subsidy liberalization lowered exports and trade, especially industrial exports, attenuating industrialization. Thus, these effects of trade reform were individually powerful, but negated each other. Korea's subsidy reform dominated quantitatively; relative to a "no reform" regime which maintains both 1963 tariff and subsidy rates forever, observed trade reform produces comparable but lower trade volumes, a larger agricultural and lower industrial employment share, and slower industrialization. "Complete reform", lowering tariffs and subsidies to zero from 1963 onwards, would have substantially increased trade volumes and facilitated industrialization.
\end{abstract}

JEL Codes: F13, F14, F43, O14, O41

Key Words: Trade policy, comparative advantage, industrialization, structural change.

${ }^{a}$ We are grateful to participants at the Midwest Macroeconomics Meetings and the Midwest Theory, Midwest International Trade Meetings, and the seminar participants at ITAM Business School for helpful comments and suggestions. We also thank Kei Mu-Yi and Murat Ungor for numerous discussions. All remaining errors are ours.

${ }^{\mathrm{b}}$ Caroline Betts, Department of Economics, University of Southern California, 3620 South Vermont Ave. Kaprielian Hall 300, Los Angeles, CA 90089, Tel: +1 2137408335, E-mail: cbetts@usc.edu.

${ }^{\mathrm{c}}$ Rahul Giri, Centro de Investigación Económica (CIE), Instituto Tecnológico Autónomo de México, Av. Camino Santa Teresa 930, Col. Héroes de Padierna, Del. Magdalena Contreras C.P. 10700 México, D.F., Tel: +52 5556284000, E-mail: rahul.giri@itam.mx.

${ }^{\mathrm{d}}$ Rubina Verma, Department of Business Administration, Instituto Tecnológico Autónomo de México, Av. Camino Santa Teresa 930, Col. Héroes de Padierna, Del. Magdalena Contreras C.P. 10700 México, D.F., Tel: +52 5556284000, E-mail: rubina.verma@itam.mx. 


\section{Introduction}

Increased international trade, export promotion, and trade liberalization policies have been coincident with massive changes in the structure, as well as the size, of the South Korean economy since 1963. Structural change has been temporally associated with trade policy shifts in other Asian countries as well, including China, the remaining "Tigers" - Hong-Kong, Singapore, and Taiwan - and the East Asian "Tiger Cubs" - Indonesia, Malaysia, the Philippines, and Thailand. Among these countries, Korea's development strategy in the late 1960s and 1970s represents a quintessential example of how export subsidies and tariffs were combined across sectors and over time to incentivize industrialization. High export subsidies were combined with a falling agricultural tariff rate, and a relatively high industrial tariff rate through 1979, while the employment share of agriculture in Korea declined dramatically and that of the industrial sector rose. From 1980 onwards dramatic industrial tariff reductions and the elimination of export subsidies coincided with continued growth in Korea's industrial employment share, nonetheless, after 1990 de-industrialization was observed. The goal of this paper is to quantify the role that trade policies played for these sectoral reallocations of employment in Korea- "structural change" - from 1963 through 2000.

Several recent studies of the structural change accompanying the Korean growth miracle have measured the role of openness and of trade costs, broadly defined, for the pace and attributes of this transformation. However, none have isolated or measured the evolution of Korea's tariff and subsidy policies over time and sectors, or its impact on industrialization. The current paper seeks to fill this void. Our contribution is three-fold. First, we construct time-series data on Korean tariff and export subsidy rates by sector for the period 1963 through 2000. Second, we apply these data to a quantitative general equilibrium model which delivers a clear mapping from trade policies to structural variables. Third, since our general equilibrium model features value added production, we carefully construct and calibrate the model using value added rather than gross Korean trade flows by sector. Our counterfactual experiments demonstrate that, although reforming one policy instrument at a time - tariff or subsidy rate - has powerful consequences for international trade and structural change, the impact of Korea's actual trade reform for sectoral reallocations is muted because the effects of tariff and subsidy reform offset each other. Export subsidy reform reduced the international competitiveness of the Korean industrial sector while tariff reform - at least until 1979 - increased this competitiveness. We find that the effects of subsidy reform quantitatively dominated those of tariff reform, so overall Korea's trade reform attenuated 
the pace and magnitude of industrialization. Industrialization was, instead, primarily driven by international specialization and income effects resulting from relatively rapid productivity growth in the Korean industrial sector.

Our framework is similar to that of Uy, Yi and Zhang (2013), featuring two countries, three sectors - agriculture, industry, and services - which in our model produce only value added with labor the sole factor of production, and constant elasticity of substitution (CES) preferences with a subsistence consumption requirement in agriculture. While Uy, Yi and Zhang (2013) adopt the Ricardian framework of Eaton and Kortum (2002) to motivate both inter-sector and intra-sector trade, we model inter-sector trade based on Ricardian comparative advantage but intra-sector trade based on Armington aggregation of domestic and foreign varieties of each sector's value added by firms producing that sector's final, non-traded consumption good. In contrast to Uy, Yi and Zhang (2013) where all trade barriers are modeled as iceberg costs, in our framework a government in each country offers proportional price subsidies on exports, imposes proportional tariffs on imports, and rebates tariff income net of subsidy expenditure to households as a lump-sum transfer. In addition, the weight on the domestic relative to the foreign variety in each sector's Armington aggregator, or the degree of "home bias", captures all real costs of trade except the policies we model explicitly import tariffs and export subsidies - including (quantitative) policy trade barriers, such as import quotas. We assume that service sector value added is non-traded, which is proximately true in the first half of our sample period, and that value added trade in agriculture and industry is balanced as it is, roughly, on average.

The model implies that the employment share of a sector is the sum of domestic and foreign final good producers' expenditure on a country's variety of that sector's good, relative to total domestic value added. These expenditures are determined by four factors: (i) the sector and country specific degrees of home bias faced by domestic and foreign final good producers; (ii) the producer price of the domestic relative to the foreign variety adjusted for tariffs and subsidies, which influences the relative intensity of the domestic variety's use by firms; (iii) relative consumer prices of final goods within a country, which incorporate the prices of domestic and imported varieties and influence the household consumption expenditure on each sector's final good; and (iv) domestic and foreign incomes inclusive of net government transfers, which dictate the level of total consumption expenditure in each country on the three final goods. Three crucial parameters influence the qualitative and quantitative responses of variety expenditure to these factors. 
First, the larger is the Armington elasticity of substitution between varieties the more responsive is the expenditure of final good producers to a change in their relative price, whether due to a change in relative labor productivity and wage rates across countries - which determine relative producer prices - or to a change in a tariff or subsidy rate which affect purchasers' prices. Second, we follow the structural change literature in assuming that final consumption goods of the three sectors are gross complements in preferences so that the elasticity of substitution between final consumption goods is less than one. Consequently, changes in the consumer price of a sector's final good cause that sector's consumption share to move in the same direction. Third, the larger is required subsistence consumption in agriculture, the faster the rate at which domestic consumption expenditure is reallocated away from the income inelastic good - agriculture - and into the income elastic goods - industry and services.

We calibrate the model to match sectoral value added data from Korea and the OECD over the period 1963 to 2000. We estimate and input Korean and OECD time series of sector-specific labor productivity, tariff rates, and export subsidy rates. Notably, there is insufficient data for us to estimate Korean agricultural subsidies and we are forced to use industrial subsidy rates in both traded good sectors. The Armington aggregator weights are matched to a sample of average expenditures on domestic and imported value added for each traded good sector and country, using value added export data for each country, after controlling for measured trade policies and the relative price of imports observed in the data. Since in our model all production is value added, we compute new, bilateral value added trade flows between Korea and the OECD and use these in our calibration. Finally, the subsistence consumption requirement in agriculture is calibrated to match the 1963 employment share of agriculture observed in Korea. This benchmark version of the model generates sectoral reallocations of employment in Korea that are qualitatively and quantitatively similar to those in the data.

Specifically, the model captures the magnitude of decline in Korean agriculture's employment share well, implying 108 percent of the actual decline. It over-estimates Korean industry's 1963 employment share, and hence under-estimates the initial service sector share. Nonetheless, from 1965 until 1980 the model's implied employment share for industry moves very closely with the data, and captures 78 percent of the observed increase between 1965 and 1991. It also captures almost 90 percent of the observed decline in industry's employment share - de-industrialization - after 1991. However, in the benchmark model, industry's employment share peaks in 1980 and declines 
thereafter, while the actual peak occurs in 1991. Consequently, services account for a larger fraction of employment towards the end of the sample period than actually observed. In addition, the model implies value added trade volumes between the OECD and Korea that are quantitatively similar to those in the data. Finally, the model implies a pattern of international trade and specialization that favors Korean industry relative to agriculture at every date, partly reflecting the pattern of comparative cost advantage measured by estimated labor productivities, but also higher estimated Korean home bias in industry relative to agriculture and the converse pattern in the OECD, and the relative importance of agricultural subsistence expenditure in Korea. It is also these factors which together produce the broad contours of structural change that the benchmark model implies, while Korean trade reform - although important for short-run fluctuations in sectoral allocations has relatively muted secular effects as we now describe.

Several counterfactual experiments quantify the impact for structural change of Korea's trade policies. First, we counterfactually maintain tariffs at their high 1963 values throughout the sample, abstracting from the reform that subsequently occurred, while inputting our original data series for subsidy rates and OECD tariffs. Maintaining 1963 tariffs, which are relatively high in agriculture, increases protection for Korean varieties - and reduces imports of OECD varieties - especially in agriculture - triggering a Korean trade surplus. Trade balance is restored because Korean expenditure switches to domestic from OECD varieties, increasing the demand for labor, wage rate, and hence producer prices and income in Korea. The resulting loss of international competitiveness for Korean exports, especially in the positive net export sector - industry, and the wage income driven increases in consumer expenditure together eliminate the incipient trade surplus that counterfactually high tariffs encourage. Overall, trade is lower, the pattern of trade is compressed, with net exports of industry and net imports of agriculture reduced, industrialization in Korea is muted, and agriculture's employment share increased relative to the benchmark model and the data. By contrast, counterfactually maintaining subsidies at their high 1963 levels while inputting our original tariff series increases trade volumes, intensifies the pattern of trade, magnifies the pace and magnitude of industrialization in Korea, and reduces agriculture's employment share relative to the benchmark economy and data. Counterfactually high 1963 subsidies raise Korean exports, and especially the exports of the internationally competitive sector - industry, inducing a trade surplus. The increase in OECD demand for Korean relative to OECD varieties restores trade balance, by stimulating relative Korean labor demand, wages, producer prices and income, and hence imports. 
A counterfactually high import tariff and counterfactually high export subsidy have the same effect on the price of Korean varieties relative to OECD varieties and intra-sector trade - they make Korean varieties relatively cheap, and stimulate producing expenditure switching in their favor compared to OECD varieties. Tariffs accomplish this in Korea by increasing the price of imported OECD varieties, while subsidies accomplish this in the OECD by reducing the price of exported Korean varieties. The resulting expenditure switching towards Korean varieties which increases Korean labor demand and wages, has two effects: (i) it increases the relative producer price of Korean varieties, and (ii) it increases relative Korean income and consumption expenditure. The relative price change in (i) acts as a drag on the expenditure switching towards Korean varieties, whereas the income effect in (ii) increases relative Korean expenditure on imports. This adjustment mechanism offsets the expenditure switching arising from trade policy changes, and must be sufficiently potent to restore trade balance. An immediate implication is that the requirement of balanced trade mutes the effects of trade reform and international productivity growth differentials for intra-industry relative prices and trade; it also moderates any associated inter-industry trade and shifts in international specialization due to sector-biased tariff and subsidy reform, and different sectoral degrees of home bias.

Evidently, the effects of tariff and subsidy reform for trade volumes, trade patterns, and structural change are opposing. Consequently, the trade and structural change generated by the actual Korean trade reform of both tariffs and subsidies simulated in the benchmark economy are surprisingly similar to those of a counterfactual "no reform" economy in which neither tariffs nor subsidies are reformed and both instruments remain at their 1963 values. The "no reform" economy demonstrates, however, that the effects of maintaining 1963 subsidies in increasing the competitiveness of industry dominate those of maintaining 1963 tariffs for reducing it. The magnitude of agriculture's employment share is counterfactually low throughout the sample, and industrialization counterfactually rapid, although both features are muted in the "no reform" economy relative to the "no subsidy reform" experiment due to simultaneously higher tariffs. Post 1963 subsidy reform in Korea disproportionately harmed the competitiveness of the industrial sector relative to the benefits conferred by tariff reform.

We find that if Korea had instead conducted trade reform "shock therapy", setting all tariff and subsidy rates to zero in 1963 and holding them there, trade volumes would have almost doubled relative to both the "no reform" and benchmark economies. Structural change in the "complete 
reform" economy is, however, almost indistinguishable from that in the "no reform" economy. This is because the evolution of relative variety prices and variety expenditure shares across sectors are almost identical in the two counterfactuals. When Korean trade policies are zero, international labor productivity differentials across sectors and sectoral differences in OECD tariffs solely determine this evolution. In the "no reform" economy, 1963 Korean subsidies are always equal across sectors and although the 1963 tariff rate is slightly higher in agriculture than in industry, the magnitude of this difference minimally distorts relative variety prices across sectors compared to the "complete reform" economy. Absolute magnitudes of policy trade barriers are irrelevant for sectoral allocations; sectoral differences matter.

Our analysis substantively contributes to a growing literature exploring the role of international trade for sectoral allocations of employment and value added. Most closely related to our work are Sposi (2014), Teignier (2014) and Uy, Yi and Zhang (2013). Like these authors, we find that a benchmark open economy model performs empirically substantially better than a closed economy variant, however our trade policy measurement and analysis is unique. Sposi's multicountry, three sector model, and that of Uy, Yi and Zhang (2013), features iceberg trade costs that reflect tariff and subsidy policies in principle. However, relative to our framework, the iceberg technology delivers identical mappings of trade policy - and all other real transactions costs to structural variables, and ignores the distortion of competitive equilibrium from socially optimal allocations arising from net tariff revenue rebates. Although he does not measure export subsidies, Sposi allocates a portion of the iceberg costs to estimated tariffs and finds that tariffs, measured and modeled this way, are not quantitatively important in influencing Korea's structural change. Teignier (2014) develops a small open economy model of Korean structural change, where agriculture and "non-agriculture" are the two sectors. While he can address neither industrial sector trade policy directly, nor interactions of sectoral trade policies, as we do, Teignier argues that had agricultural trade barriers been absent accelerated movements of resources out of agriculture would have resulted, which is consistent with our "shock therapy" counterfactual result. Finally, Connolly and Yi (2015) also analyze the effects of Korea's trade policies for structural variables in a general equilibrium setting. However, theirs is an analysis of the role of trade policy for economic growth, rather than for structural change. They use a neoclassical capital accumulation model, in contrast to our static Ricardian framework, and deliberately abstract from sectoral reallocations. 


\section{Structural Change and Trade Reform in South Korea}

Prior to 1963, Korea was essentially a closed economy, characterized by high unemployment and inflation, and large budget and balance of payments deficits. Import substitution policies overtly encouraged production for domestic rather than for export markets, and international trade between Korea and the rest of the world was small.

The high barriers to imports imposed by Korea in the 1950s were systematically removed starting in 1968, with selective quantitative barrier and tariff reductions for agricultural products. Subsequently, substantial industrial tariff reductions took place between 1973 and 1983, and in 1979 the industrial tariff rate finally fell below its 1963 value. Tariff reform continued into the 1990s, with the last tariff rate reductions observed in our data occurring between 1994 and 1995; the average tariff rate fell to 7.9 percent in 1995.

In addition, from 1963, a variety of export promotion policies were enacted. These initially targeted the development of key export industries, with export incentives that included direct cash subsidies, a preferential tax system, a preferential loan system, and various administrative support systems. The preferential tax system included tariff exemptions on raw materials, intermediate goods, and capital goods devoted specifically to export production. Many subsidies,however, increased the profitability of export sales relative to domestic sales by distorting international relative prices. Although export incentives remained in place throughout the 1970s, the scope of subsidies was gradually reduced. For example, a 50 percent reduction in taxes on profits from export earnings was abolished and, in 1975, the system of tariff exemptions on imported inputs used in export production was changed to a "drawback" system. While tariff exemptions on imported intermediates were an important element of Korean trade liberalization, we focus on quantifying value added in production and trade and abstract from the role of intermediate inputs, so the export subsidy data we use is net of tariff exemptions on intermediate products. Irrespective of the inclusion or exclusion of tariff exemptions, by 1982 most export subsidies had been eliminated (Nam (1995)) and in our trade policy data, which we describe in detail in section 4, the estimated gross subsidy rate falls to zero in 1981.

Figure 1 shows the evolution of Korean bilateral value added exports and imports by sector and in total with the OECD during the 1963 through 2000 period $^{1}$. A description of our construction of Korea's value added bilateral trade with the OECD is provided in section 4. OECD countries

\footnotetext{
${ }^{1}$ Accurate and complete service sector trade data is unavailable for Korea or the OECD for these years so the 'total' export and 'total' import trade measures in the figures comprise the sum of agricultural and industrial exports and imports.
} 
accounted for 68 percent of Korean gross exports and 71 percent of Korean gross imports annually on average over this period, suggesting the importance of OECD trade for the growth of Korean trade after 1963. In addition, we find that Korea exported $13 \%$ more current dollar value added to the OECD than she did to all of her trade partners in the world economy, and imported three percent more from the OECD during our sample period; the OECD was a relatively important value added trade partner for Korea.

Figure 1 shows that trade promotion policies in Korea were associated with a dramatic increase in the size and shift in the composition of her bilateral value added trade with the OECD. Total trade more than doubled over the entire 38 year period, from 10 percent of Korean GDP in 1963 to 21 percent in 2000. It reached a peak of almost 30 percent by the mid-1970s, after a period of very rapid growth in both exported and imported value added. Value added exports rose from less than 2 percent in 1963 to more than 12 percent of GDP in 2000, a more than six fold increase, reaching peaks of 13.7 percent and 15 percent of GDP in 1976 and 1987 respectively. Value added imports increased very little over all, rising from 8.3 percent of GDP in 1963 to 8.9 percent in 2000, however they reached a peak of 15 percent in 1974. Meanwhile, the composition of value added trade shifted heavily in favor of industrial sector exports and imports. Industrial sector value added exports accounted for only 21 percent of total exports of value added in 1963, but for 81.5 percent in 2000. Similarly, industrial sector value added accounted for 59 percent of total value added imports in 1963 and for 83 percent in 2000.

\section{Figure 1 goes here}

The left panel of Figure 2 shows that Korean trade reform, and the two-fold increase in the size of Korea's bilateral value added trade with the OECD, was accompanied by a dramatic rise in real gross value added (GDP) per worker ${ }^{2}$ relative to the OECD. Korean real GDP per worker rose from about 12 percent to roughly 46 percent of that in the OECD, an increase of about 277 percent over the sample period. The right panel of Figure 2 shows that this is associated with a more than 200 percent increase in relative value added per worker in the industrial sector, from about 23 percent to roughly 70 percent of that in the OECD. While Korean agriculture and service sectors also saw increases in relative value added per worker, these were dwarfed by that in the industrial sector. The right panel therefore reveals a shift in the pattern of comparative advantage in favor of Korean industrial products after the mid-1970s, when relative industrial productivity in

\footnotetext{
${ }^{2}$ The construction of real GDP per worker is described in detail in section 4 .
} 
Korea began to grow rapidly.

\section{Figure 2 goes here}

Figure 3 shows that Korea's export promotion, trade reform, trade growth, relative income growth, and labor productivity growth coincided with substantial structural transformation of the economy. The right panel of the figure shows the evolution of employment shares of the three major sectors of the economy, expressed as a percentage of total employment, and the left panel shows the evolution of GDP shares ${ }^{3}$ of the three sectors, expressed as a percentage of aggregate GDP. A large decline in the employment and GDP share of agriculture and an increase in the employment and GDP shares of the industrial and the service sector occurred between 1963 and 2000. Specifically, in 1963 agriculture accounted for 63 percent of Korean employment, and 43 percent of GDP; by 2000, these shares had declined to 11 and 5 percent respectively. By contrast, the employment and GDP shares of industry rose from 11 and 20 percent to 29 and 42 percent respectively, while those of the service sector rose from 25 and 36 percent to 61 and 53 percent. The industrial sector's employment share exhibits the "hump" shape that is highlighted in the literature on structural change, declining to 29 percent in 2000 after reaching a peak of 36 percent in 1991. GDP shares evolve rather differently from employment shares, with services showing much less GDP than employment share growth, and industry greater growth. In our analysis we focus on employment shares, which are more common measures of structural change than GDP shares.

\section{Figure 3 goes here}

This structural transformation of the Korean economy is the object of our analysis. We develop a quantitative model which, when calibrated to Korean data and simulated can address the question: To what extent was the structural transformation of Korea attributable to the international trade policies adopted there?

\section{Model}

We consider a two country, three sector world economy where the countries are "home" and "foreign" and indexed by $i=h, f$. The three sectors are "Agriculture", "Industry", and "Services" and indexed by $k=A, I, S$. Each sector exclusively produces a single final consumption good - so that final goods are also indexed by $k$ - by aggregating domestically and imported varieties of the sector's good. We assume that trade in varieties is balanced, while final goods are not traded.

\footnotetext{
${ }^{3}$ We describe the construction of the employment and GDP shares in section 4.
} 
A representative household inhabits each country, derives utility from consumption of the three sectors' final goods, and supplies labor in-elastically to variety production. Labor is mobile across sectors but not countries. Also, a government in each country imposes proportional tariffs on imports, rewards exports of varieties with proportional subsidies, and rebates tariff income net of subsidy expenditure to households as a lump-sum transfer. Consequently, competitive equilibrium allocations of this economy are not, in general, Pareto efficient. Finally, time is discrete and indexed by $t$.

\subsection{Varieties}

A representative perfectly competitive firm in sector $k$ produces the $i$ th variety using a simple linear Ricardian technology:

$$
y_{i, t}^{k}=\theta_{i, t}^{k} N_{i, t}^{k},
$$

where $\theta_{i, t}^{k}$ is the exogenous productivity of labor, $N_{i, t}^{k}$ the number of labor units employed, and $y_{i, t}^{k}$ the level of output, at date $t$, respectively. This representation of sectoral variety production is identical to that employed by Duarte and Restuccia (2010). Variety producers take the prices of output and labor as given, and choose employment to solve the profit maximization problem.

$$
\begin{gathered}
\max p_{i, t}^{k} y_{i, t}^{k}-w_{i, t} N_{i, t}^{k} \\
\text { s.t. } y_{i, t}^{k}=\theta_{i, t}^{k} N_{i, t}^{k} \text {, and } N_{i, t}^{k} \geq 0 . \quad \text { for } i=h, f, k=A, I, S \text { and } \forall t
\end{gathered}
$$

Here, $p_{i, t}^{k}$ is the producer price of variety $i$ of good type $k$, and $w_{i t}$ is the wage rate in country $\mathrm{i}$ at date $t$.

\subsection{Government}

The government in each country sets tariffs and subsidies subject to a balanced budget at every date. Specifically, government $i$ imposes a per unit tariff $-\tau_{i, j, t}^{k}$ - on units of variety $j \neq i$ for sector $k=A, I$, imported from abroad by domestic final good producers. It also awards subsidies for units of variety $i$ exported by reducing the unit price paid by producer $k=A, I$ in country $j \neq i$ by a proportionate factor $\frac{s_{i, j, t}^{k}}{1+s_{i, j, t}^{k}}$ which it pays directly to the exporting variety producer. The unit price paid by country $j \neq i$ importers for variety $i$ of good $k$ is therefore $\frac{p_{i, t}^{k}}{1+s_{i, j, t}^{k}}$. Country $j$ tariffs are levied on this value as goods cross the border. Since tariff revenue net of expenditure on export subsidies is rebated to the consumer as a lump sum transfer, the budget constraint of government 
$i, i \neq j$ is

$$
T_{i t}=\sum_{k} \tau_{i, j, t}^{k} \frac{p_{j, t}^{k}}{\left(1+s_{j, i, t}^{k}\right)} y_{j, i, t}^{k}-\sum_{k} \frac{s_{i, j, t}^{k}}{\left(1+s_{i, j, t}^{k}\right)} p_{i, t}^{k} y_{i, j, t}^{k} \quad \text { for } k=A, I, \forall t
$$

Here $y_{j, i, t}^{k}$ is country $i$ imports of variety $j$ of good $k$ and $y_{i, j, t}^{k}$ is country $i$ exports of variety $i$ to country $j$ of good $k, i \neq j$.

\subsection{Final Goods}

A representative perfectly competitive firm in sector $k$ of country $i \neq j$ produces final good $k$ with the production function, where we assume that Service varieties are not traded, i.e we set $\mu_{i}^{S}=1$, for $i=h, f$ :

$$
Y_{i, t}^{k}=\left(\mu_{i}^{k}\left(y_{i, i, t}^{k}\right)^{\rho}+\left(1-\mu_{i}^{k}\right)\left(y_{j, i, t}^{k}\right)^{\rho}\right)^{1 / \rho} \text { for } k=A, I, S
$$

Here, $Y_{i, t}^{k}$ is total final output of good $k, y_{i, i, t}^{k}$ and $y_{j, i, t}^{k}$ are domestic variety $i$ and imported variety $j$ inputs respectively, $\mu_{i}^{k}$ is the weight assigned to the domestic variety of traded goods, $\left(1-\mu_{i}^{k}\right)$ is the weight assigned to the imported variety, and $\rho$ reflects the elasticity of substitution between these varieties. Following convention in the international trade literature, the domestic and foreign varieties are substitutes, or $0<\rho<1$. The values of $\mu_{i}^{k}$ and $\rho$ are important determinants of final good producers' allocation of spending on local and imported varieties of inputs, and hence of the pattern and volume of trade. We think of $\mu_{i}^{k}$ as a reduced form "home bias" parameter; it captures primitive technological and preference factors which encourage use of locally produced relative to imported varieties. These factors include all real costs of trade, except the domestic country proportional tariffs and reductions in foreign country subsidies which are explicitly modeled and discourage imported variety use, including any policy barriers such as import quotas which we do not explicitly model.

Final good producers of sector $k$ in country $i \neq j$ take prices as given, as well as the government policies that they confront, and solve the following profit maximization problem:

$$
\begin{gathered}
\max P_{i, t}^{k} Y_{i, t}^{k}-p_{i, t}^{k} y_{i, i, t}^{k}-\frac{\left(1+\tau_{i, j, t}^{k}\right)}{\left(1+s_{j, i, t}^{k}\right)} p_{j, t}^{k} y_{j, i, t} \\
\text { s.t. } Y_{i, t}^{k}=\left(\mu_{i}^{k}\left(y_{i, i, t}^{k}\right)^{\rho}+\left(1-\mu_{i}^{k}\right)\left(y_{j, i, t}^{k}\right)^{\rho}\right)^{1 / \rho} .
\end{gathered}
$$

$P_{i, t}^{k}$ is the consumer price index for good $k$, which is derived from the first order conditions of final 
good producers, and given by ${ }^{4}$

$$
P_{i, t}^{k}=\left(\left(\mu_{i}^{k}\right)^{1 /(1-\rho)}\left(p_{i, t}^{k}\right)^{\rho /(\rho-1)}+\left(1-\mu_{i}^{k}\right)^{1 /(1-\rho)}\left(\frac{\left(1+\tau_{i, j, t}^{k}\right)}{\left(1+s_{j, i, t}^{k}\right)} p_{j, t}^{k}\right)^{\rho /(\rho-1)}\right)^{\frac{(\rho-1)}{\rho}}
$$

\subsection{Households}

Household $i$ maximizes the lifetime utility function

$$
\max U^{i}\left(C_{i}\right)=\sum_{t=0}^{\infty} \beta^{t} \frac{C_{i, t}^{\psi}-1}{\psi},
$$

where $0<\beta<1$ is a subjective time discount factor and $C_{i, t}$ comprises a composite of the three types of final good.

$$
C_{i, t}=\left(\xi_{A}\left(C_{i, t}^{A}-\bar{A}\right)^{\omega}+\xi_{I}\left(C_{i, t}^{I}\right)^{\omega}+\xi_{S}\left(C_{i, t}^{S}\right)^{\omega}\right)^{\frac{1}{\omega}}
$$

Here, $C_{i, t}^{A}, C_{i, t}^{I}$ and $C_{i, t}^{S}$ are household $i$ 's consumption of Agriculture, Industry, and Services respectively, and $\bar{A}$ denotes subsistence consumption of Agriculture. In addition, $\xi_{k}$ is the weight assigned to consumption of final good $k, \omega$ governs the elasticity of substitution between the three types of final good, and $\psi$ governs the elasticity of inter-temporal substitution. Preference parameters are assumed to be identical across countries ${ }^{5}$.

Household $i$ maximizes lifetime utility (3.5) by choice of consumption of each type of good, subject to (3.6) and the budget constraint

$$
\sum_{k} P_{i, t}^{k} C_{i, t}^{k}=w_{i, t} N_{i, t}+T_{i, t} \quad \forall t
$$

where $N_{i, t}$ is the household's endowment of productive time which we normalize to one unit, and is inelastically supplied. Without loss of generality, we let the foreign produced variety of industrial goods be the numeraire at every date.

\subsection{Equilibrium}

A competitive equilibrium is an allocation $\left\{C_{i, t}, C_{i, t}^{A}, C_{i, t}^{I}, C_{i, t}^{S}\right\}_{t=0}^{\infty}$ for household $i$; an allocation $\left\{N_{i, t}^{k}, y_{i, t}^{k}\right\}_{t=0}^{\infty}$ for variety producer $i$ of sector $k$; an allocation $\left\{y_{i, i, t}^{k}, y_{j, i, t}^{k}, Y_{i, t}^{k}\right\}_{t=0}^{\infty}$ for final good producer $k$ in country $i, i \neq j$; prices $\left\{w_{i, t}, p_{i, t}^{k}, P_{i, t}^{k}\right\}_{t=0}^{\infty}$ for country $i$ and sector $k$; and exogenous

\footnotetext{
${ }^{4}$ Since $\mu_{i}^{S}=1, P_{i, t}^{S}=p_{i, t}^{S}$.

${ }^{5} \mathrm{~A}$ generalized form of the utility function allowing for non-homothetic preferences in the industrial and service sectors can be expressed as

$$
C_{i, t}=\left(\xi_{A}\left(C_{i, t}^{A}-\bar{A}\right)^{\omega}+\xi_{I}\left(C_{i, t}^{I}+\bar{I}\right)^{\omega}+\xi_{S}\left(C_{i, t}^{S}+\bar{S}\right)^{\omega}\right)^{\frac{1}{\omega}}
$$

. Uy, Yi and Zhang (2013) find the estimate of $\bar{S}$ to be zero using Korean data. We restrict $\bar{I}$ to be zero following Herrendorf, Rogerson and Valentinyi (2013)
} 
government policies $\left\{\tau_{i, j, t}^{k}, s_{i, j, t}^{k}, T_{i, t}\right\}_{t=0}^{\infty}$ for $i=h, f, i \neq j$, and $k=A, I, S$; such that for $i=h, f$ and $k=A, I, S$,

(1) Given prices and policies, household i's allocation solves the maximization problem ((3.5), subject to (3.6) and (3.7));

(2) Given prices, variety $i$ producer's allocation solves the maximization problem (3.1) $\forall t$;

(3) Given prices and policies, final good $k$ producer's allocation solves the maximization problem (3.3) $\forall t$;

(4) Prices are such that labor markets clear

$$
\sum_{k} N_{i, t}^{k}=N_{i, t} \forall t
$$

variety markets clear

$$
\begin{gathered}
y_{i, t}^{k}=y_{i, i, t}^{k}+y_{i, j, t}^{k}, \text { for } k=A, I \text { and } \forall t, \\
y_{i, t}^{k}=y_{i, i, t}^{k}, \text { for } k=S \text { and } \forall t,
\end{gathered}
$$

and final goods markets clear

$$
Y_{i, t}^{k}=C_{i, t}^{k} \forall t
$$

(5) Government i's budget constraint is satisfied:

$$
T_{i t}=\sum_{k} \tau_{i, j, t}^{k} \frac{p_{j, t}^{k}}{\left(1+s_{j, i, t}^{k}\right)} y_{j, i, t}^{k}-\sum_{k} \frac{s_{i, j, t}^{k}}{\left(1+s_{i, j, t}^{k}\right)} p_{i, t}^{k} y_{i, j, t}^{k} \forall t .
$$

\subsection{Analysis}

The first order conditions for a variety producer's profit maximization problem imply that labor is paid the value of its marginal product if that variety is produced so that $p_{i, t}^{k}=\frac{w_{i, t}}{\theta_{i, t}^{k}}$. The first order conditions for profit maximization of final good producer $k$ in country $i \neq j$ imply that the shares of expenditure on final good type $k$ in country $i$ accounted for by varieties $i$ and $j$ respectively are given by

$$
\begin{gathered}
Z_{i, i, t}^{k}=\frac{p_{i, t}^{k} y_{i, i, t}}{P_{i, t}^{k} Y_{i, t}^{k}}=\left(\mu_{i}^{k}\right)^{\frac{1}{1-\rho}}\left(\frac{p_{i, t}^{k}}{P_{i, t}^{k}}\right)^{\frac{\rho}{\rho-1}} \\
Z_{j, i, t}^{k}=\frac{\frac{\left(1+\tau_{i, j, t}^{k}\right)}{\left(1+s_{j, i, t}^{k}\right.} p_{j, t}^{k} y_{j, i, t}^{k}}{P_{i, t}^{k} Y_{i, t}^{k}}=\left(1-\mu_{i}^{k}\right)^{\frac{1}{1-\rho}}\left(\frac{\frac{\left(1+\tau_{i, j, t}^{k}\right)}{\left(1+s_{j, i, t}^{k}\right.} p_{j, t}^{k}}{P_{i, t}^{k}}\right)^{\frac{\rho}{\rho-1}} .
\end{gathered}
$$


For Services $Z_{j, i, t}^{S}=0$. Finally, market clearing for final good $k$ implies that $P_{i, t}^{k} Y_{i, t}^{k}=P_{i, t}^{k} C_{i, t}^{k}$ for $i=h, f$ and $k=A, I, S \forall t$.

The first order conditions for the household's intra-temporal problem combined with the budget constraint yield the size of expenditure on each type of good relative to the total final expenditure on the consumption composite for country $i=h, f$.

$$
E_{i, t}^{k} \equiv \frac{P_{i, t}^{k} C_{i, t}^{k}}{\Xi_{i, t}}= \begin{cases}\frac{\xi_{k}^{\frac{1}{1-\omega}}\left(P_{i, t}^{k}\right)^{\frac{\omega}{\omega-1}}}{\sum_{m=\{A, I, S\}} \xi_{m}^{1-\omega}\left(P_{i, t}^{m}\right)^{\frac{\omega}{\omega-1}}}\left(1-\frac{P_{i, t}^{A} \bar{A}}{\Xi_{i, t}}\right)+\frac{P_{i, t}^{A} \bar{A}}{\Xi_{i, t}}, & \text { if } k=A \\ \frac{\xi_{k}^{1-\omega}\left(P_{i, t}^{k}\right)^{\frac{\omega}{\omega-1}}}{\sum_{m=\{A, I, S\}} \xi_{m}^{\frac{1}{1-\omega}}\left(P_{i, t}^{m}\right)^{\frac{\omega}{\omega-1}}}\left(1-\frac{P_{i, t}^{A} \bar{A}}{\Xi_{i, t}}\right), & \text { if } k=I, S,\end{cases}
$$

where $\Xi_{i, t}=\sum_{k} P_{i, t}^{k} C_{i, t}^{k}$ is total final expenditure on the consumption composite.

Finally, the balanced trade or world payments equilibrium condition for our economy is derived from the consumer's budget constraint, and is, for country $i=h, f, i \neq j$

$$
\sum_{k=A, I} \frac{1}{1+s_{i, j, t}^{k}} p_{i, t}^{k} y_{i, j, t}^{k}=\sum_{k=A, I} \frac{1}{1+s_{j, i, t}^{k}} p_{j, t}^{k} y_{j, i, t}^{k}
$$

That is, the effective world prices at which trade occurs between importing final good producers and exporting variety producers are producer prices adjusted for export subsidies ${ }^{6}$.

\subsubsection{Employment Structure}

GDP at factor cost in country $i$ at date $t$ is just the sum of the value of outputs of each sector's variety, $Y_{i, t}=\sum_{k} p_{i, t}^{k} y_{i, t}^{k}$. Profits are zero in equilibrium, and labor is the only production factor, so GDP at factor cost is also measured by labor income at $t, Y_{i, t}=w_{i, t} \sum_{k} N_{i, t}^{k}=w_{i, t} N_{i, t}$. Therefore, the GDP and employment share of a sector are identical:

$$
\frac{p_{i, t}^{k} y_{i, t}^{k}}{Y_{i, t}}=\frac{N_{i, t}^{k}}{N_{i, t}} . \forall t
$$

It is worth mentioning that in our framework GDP is valued differently depending on whether prices of goods are measured before or after taxes and subsidies. The use of prices excluding taxes and subsidies yields GDP at factor cost, while the use of prices including taxes and subsidies yields GDP

\footnotetext{
${ }^{6}$ We do not explicitly model subsidies as being given to exporters as a production subsidy for the sake of simplicity. However, like a production subsidy for exports, subsidies in our framework lower the price paid for units that are exported relative to units that are purchased domestically. Since subsidies affect the price at which a variety reaches the border of the destination market, the balanced trade condition must hold at prices that are inclusive of subsidies. Tariffs, on the other hand, affect the price only after the good has crossed the border, and implicate the consumer prices of imports but not the price at which goods are exchanged across the border. Thus, tariffs do not appear in the balanced trade condition. Alternatively, we can think of our formulation of subsidies as being a simplification of the underlying production technology for exporting, while the tariff is a tax on imports.
} 
at purchaser prices. We choose to measure the GDP shares of sectors by valuing GDP at factor cost. Therefore, when we quantify our model and in the data presented in section 2 , we employ as our data counterparts factor cost measures of sectoral and aggregate GDP, and of sectoral GDP per worker, drawn from the World Development Indicators (WDI) database of the World Bank. Also, in our model, while the employment share of a sector equals its share in GDP valued at factor cost, this equality does not hold when GDP is valued at purchaser prices. Therefore, the presence of taxes and subsidies can generate a discrepancy between the output and employment share of a sector even with a Ricardian production technology. However, our focus in this paper is on employment shares since they have been the subject of investigation in much of the literature on structural change.

We now characterize the determinants of the economy's structure in terms of the employment shares of each sector $k$. From the variety market clearing condition, the value added of variety $i$ output in sector $k$ equals the sum of domestic consumption and exports valued at factor cost, or

$$
p_{i, t}^{k} y_{i, t}^{k}=p_{i, t}^{k}\left(y_{i, i, t}^{k}+y_{i, j, t}^{k}\right) \forall t
$$

where exports are zero for services. Dividing this by $w_{i, t} N_{i, t}$ and using (3.12) yields

$$
\frac{p_{i, t}^{k} y_{i, t}^{k}}{Y_{i, t}}=\frac{N_{i, t}^{k}}{N_{i, t}}=\frac{p_{i, t}^{k}\left(y_{i, i, t}^{k}+y_{i, j, t}^{k}\right)}{w_{i, t} N_{i, t}}=\left(\frac{p_{i, t}^{k} y_{i, i, t}^{k}}{P_{i, t}^{k} Y_{i, t}^{k}}\right)\left(\frac{P_{i, t}^{k} Y_{i, t}^{k}}{w_{i, t} N_{i, t}}\right)+\left(\frac{p_{i, t}^{k} y_{i, j, t}^{k}}{P_{j, t}^{k} Y_{j, t}^{k}}\right)\left(\frac{P_{j, t}^{k} Y_{j, t}^{k}}{w_{i, t} N_{i, t}}\right)
$$

Using (3.8), (3.9), (3.10), the final goods' market clearing conditions, and the budget constraints of households, the share of employment accounted for by sector $k$ at date $t$ equals:

$$
V_{i, t}^{k}=Z_{i, i, t}^{k} E_{i, t}^{k}\left(1+\frac{T_{i t}}{w_{i, t} N_{i, t}}\right)+\left(\frac{1+s_{i, j, t}^{k}}{1+\tau_{j, i, t}^{k}}\right) Z_{i, j, t}^{k} E_{j, t}^{k}\left(1+\frac{T_{j t}}{w_{j, t} N_{j, t}}\right) \frac{w_{j, t} N_{j, t}}{w_{i, t} N_{i, t}},
$$

where $Z_{i, i, t}^{k}$ is given by (3.8), $Z_{i, j, t}^{k}$ can be derived using (3.9), and $E_{i, t}^{k}$ is given by (3.10). For the service sector, since $\mu_{i}^{k}=1, Z_{i, i, t}^{S}=1$, and therefore

$$
V_{i, t}^{S}=E_{i, t}^{k}\left(1+\frac{T_{i t}}{w_{i, t} N_{i, t}}\right)
$$

Equation (3.13) illustrates that the employment share of traded sector $k$ in country $i$ depends on two core forces. One force originates from the consumption side of the economy, and measures the relative magnitude of home and foreign final consumer demand for the sector $k$ good, given by the home and foreign consumption expenditure shares of the sector, $E_{i, t}^{k}$ and $E_{j, t}^{k}$. The second force originates from the production side of the economy, and captures the relative magnitude of 
world producer demand for country $i$ 's variety of the sector $k$ good. This is measured by the share of country $i$ 's variety in the expenditure of final good $k$ producers at home and abroad, $Z_{i, i, t}^{k}$ and $Z_{i, j, t}^{k}$ respectively.

We call the first term on the right-hand side of equations (3.13) and (3.14) the "domestic effect" for a sector's employment share, which equals the share of value added accounted for by domestic expenditure on the domestic variety of the sector. For the Service sector, which produces the non-traded portion of GDP, the domestic effect is simply the domestic consumption expenditure share of the sector which wholly constitutes its employment share. While Services are not traded, their employment share (3.14) is potentially influenced in an open economy by international trade, because the price of the domestic variety of Services relative to the price indexes of traded goods included in the CPI, is a determinant of the sector's domestic consumption expenditure share, as seen in (3.10). Analogously, the second term on the right-hand side of (3.13) captures the "foreign effect" for a sector's employment share in a country, which equals the share of domestic value added accounted for by foreign expenditure on the domestic variety -exports of the sector.

\subsubsection{Structural Change in the Open Economy}

By structural change, we refer to (secular) change over time in the employment shares of sectors. We first describe structural change in a closed economy version of our model, in which the foreign effect is zero and there is no indirect effect of trade on the domestic effect through relative prices. Furthermore, net transfers are zero. Therefore, the employment share of a sector is simply its final consumption expenditure share,

$$
V_{i, t}^{k}=E_{i, t}^{k}
$$

The final consumption expenditure share of a sector depends on its relative final consumer price, which in the closed economy equals its relative producer price and is determined by the inverse

of its relative labor productivity, $p_{i, t}^{k} / p_{i, t}^{k^{\prime}}=\theta_{i, t}^{k^{\prime}} / \theta_{i, t}^{k}$. The direction and magnitude of a sector's consumption spending response to changes in its relative price are dictated by the elasticity of substitution between final goods in preferences. In our calibrated model, and throughout the structural change literature, this elasticity is assumed to be sufficiently small that final goods are gross complements, i.e. $\omega$ is negative, so that a decrease in the relative price of final good $k$ results in a decline in its expenditure share. This reallocates labor away from sectors with relatively fast productivity growth, and hence falling relative prices, and, in favor of sectors with relatively slow 
productivity growth and rising relative prices. For Korea, productivity growth in industry was the fastest followed by agriculture and services (in that order), so as the price of services rises relative to that of both agriculture and industry, the consumption expenditure and employment shares of the sector rise in the closed economy. The price of agriculture also increases relative to that of industry, implying that the consumption expenditure and employment share of industry unambiguously decline through this mechanism. The behavior of agriculture's expenditure and employment shares is ambiguous, falling relative to that of services and increasing relative to that of industry. For industry to exhibit the hump-shape pattern observed in the data - an increase followed by a decline - would require that its productivity growth rate lie between that of agriculture and services, which was not the case for Korea from 1963-2000; here, the only sector that potentially exhibits hump shape in its employment share as the result of relative price changes is agriculture.

However, our model also features an income effect due to non-homothetic preferences. The subsistence consumption requirement in agriculture implies that agricultural consumption has a lower income elasticity (less than one) than consumption of industry and services. The agricultural sector can have a high employment share at very low levels of income because of the binding subsistence consumption requirement. However, as income increases with labor productivity growth, subsistence consumption ceases to be a constraint and consumption expenditure shifts towards industry and services. This exacerbates the increase in services' employment share due to relative price effects, offsets the relative price induced decrease in industry's share, and depresses agriculture's employment share (the response of which to relative prices is ambiguous). Whether this channel is strong enough to offset the relative price effect for industry in the early years of the sample, facilitating a hump-shape pattern for the industrial sector's employment share in a closed economy, is a quantitative question; we find in section 5.2 that it not.

How does opening to trade affect structural change, and how can it help the hump-shape pattern of industrialization? According to (3.13), both the domestic and foreign effect determine the employment share of a sector in the open economy. While the foreign effect captures the direct role of trade for structural change, the domestic effect is also affected by trade through the relative prices of imported varieties. Trade breaks the tight mapping between domestic demand for a sector's goods and its employment share observed in the closed economy. At low levels of income, due to the subsistence requirement, agriculture has a high share in employment as it does in the closed economy. Over time, two opposing relative price forces can generate structural change 
in Korea; (a) changes in relative consumer prices of final goods in Korea and the OECD, and (b) changes in the international relative variety prices of Korean goods. When Korea's relative labor productivity growth in industry is sufficiently fast, (a) exerts a downward force on the employment share of industry in Korea due to a declining relative consumer price of industrial goods in Korea and, potentially, the OECD, while (b) exerts an upward force by unambiguously increasing both domestic and foreign final good producer demand for Korean industrial goods. We may conjecture that initially (b) will dominate (a), with rapid Korean industrial productivity growth implying that large gains from trade are possible for an initially very closed and (wage) poor economy, resulting in an unambiguous increase in industry's employment share and, because the share of services also tends to rise due to its relative consumer price increasing, an unambiguous decrease in agriculture's share. However, as specialization due to trade continues, relatively high world demand for Korean industrial varieties raises Korean labor demand, wages, and producer prices. Overtime, (b) is likely to (at least) weaken relative to (a). In addition, reallocations of employment from agriculture into industry and services due to income effects are muted over time as the impact of the subsistence requirement diminishes, so non-homethetic preferences reinforce a hump-shaped pattern of industrialization, the decline in agriculture's employment share, and the systematic increase in services employment share.

The model's ability to generate the hump shape pattern depends on the relative strength of (b), and this depends crucially on the degree of substitutability between domestic and foreign varieties measured by the Armington elasticity, $(\rho)$. To see this, we re-write the expressions for the share of domestic and foreign varieties in the expenditure on sector $k$ goods (in (3.13)) using the definition of price indices in (3.4) and the first order conditions of variety producers,

$$
\begin{aligned}
Z_{i, i, t}^{k}=\left(\mu_{i}^{k}\right)^{\frac{1}{1-\rho}}\left(\frac{p_{i, t}^{k}}{P_{i, t}^{k}}\right)^{\frac{\rho}{\rho-1}}=\left[1+\left(\frac{1-\mu_{i}^{k}}{\mu_{i}^{k}}\right)^{\frac{1}{1-\rho}}\left(\frac{\left(1+\tau_{i, j, t}^{k}\right)}{\left(1+s_{j, i, t}^{k}\right.} \frac{w_{j, t}}{w_{i, t}} \frac{\theta_{i, t}^{k}}{\theta_{j, t}^{k}}\right)^{\frac{\rho}{\rho-1}}\right]^{-1}, \\
Z_{i, j, t}^{k}=\left(1-\mu_{j}^{k}\right)^{\frac{1}{1-\rho}}\left(\frac{1+s_{i, j, t}^{k}}{1+\tau_{j, i, t}^{k}}\right)^{\frac{1}{1-\rho}}\left(\frac{p_{i, t}^{k}}{P_{j, t}^{k}}\right)^{\frac{\rho}{\rho-1}} \\
=\left(\frac{1+s_{i, j, t}^{k}}{1+\tau_{j, i, t}^{k}}\right)\left[1+\left(\frac{\mu_{j}^{k}}{1-\mu_{j}^{k}}\right)^{\frac{1}{1-\rho}}\left(\frac{\left(1+s_{i, j, t}^{k}\right)}{\left(1+\tau_{j, i, t}^{k}\right)} \frac{w_{j, t}}{w_{i, t}} \frac{\theta_{i, t}^{k}}{\theta_{j, t}^{k}}\right)^{\frac{\rho}{\rho-1}}\right]^{-1} .
\end{aligned}
$$

In (3.15), since we assume that foreign and domestic varieties are substitutes, $0<\rho<1$. If $\frac{\left(1+\tau_{i, j, t}^{k}\right)}{\left(1+s_{j, i, t}^{k}\right)} \frac{w_{j, t}}{w_{i, t}} \frac{\theta_{i, t}^{k}}{\theta_{j, t}^{k}}$ increases over time, the price of variety $i$ confronted by domestic final good $k$ pro- 
ducers falls relative to that of the foreign variety, and the share of sector $k$ in domestic employment rises due to more intensive domestic use of the domestic variety and a larger domestic effect. This occurs when the sector $k$ domestic tariff rate increases relative to the foreign subsidy rate, when domestic sector $k$ labor productivity increases relative to that abroad, and when the relative domestic wage falls. Similarly, in (3.16), increases in domestic subsidies relative to foreign tariffs, in relative domestic labor productivity, and decreases in the relative domestic wage promote a lower relative price and more intensive use of the domestic variety abroad. The foreign effect for sector $k$ increases, and the share of sector $k$ in country $i$ employment rises as a result. The higher is $\rho$ and hence the larger the elasticity of substitution between domestic and imported varieties, $1 /(1-\rho)$, the larger is the impact of changes in relative variety prices for sector $k$ 's variety use and share of employment.

There are, then, three main mechanisms affecting Korean structural change in our benchmark economy. First, international differences in sectoral labor productivity growth rates, as well as substantial changes in the tariff and subsidy rates in Korea, effect changes in the international relative prices and relative intensity of use of Korean and OECD varieties, implying shifts in the pattern of international trade and specialization. Second, the same factors change relative consumer prices within countries, and shift the consumption expenditure patterns across sectors. Third, income effects due to the subsistence consumption requirement in agriculture reallocate resources out of agriculture in Korea and into industry and services, although at a diminishing rate.

\section{Calibration and Data}

We calibrate the model of Section 3 to data from South Korea and the OECD. In our calibration, we treat Korea as the home country and the OECD as the foreign country. Wherever OECD aggregate data is not available to calibrate the parameters of the model, we substitute US data as a proxy and note in the text where this is necessary. Since China's external liberalization would inevitably play an important role in Korean trade patterns and specialization, we end the sample in 2000 to isolate the impact of opening to trade and trade reform policies of Korea.

\subsection{Data}

First we discuss our construction of some key data series, and their sources.

Value Added and GDP: We measure the GDP of a sector with sectoral value added data from the World Development Indicators (WDI) statistics, 2003. These data are measured at factor cost and are reported in current and constant 1995 US dollars, with the following definitions of sectors. 
Agriculture corresponds to ISIC divisions 1-5; these include forestry, hunting, and fishing, as well as cultivation of crops and livestock production. Industry corresponds to ISIC divisions 10-14, 1537, 40-41 and 45; these include mining, manufacturing, public utilities and construction. Services correspond to ISIC divisions 50-55, 60-64, 65-74 and 75-99; these include wholesale and retail trade (including hotels and restaurants), transport, storage and communication, finance, insurance and real estate and community, and social and personal services. Missing values of constant 1995 dollar value added in industry and services for Korea for 1963-69 were imputed using that sector's growth rate of real value added during 1970-80. Real value added by sector for OECD member countries is only available from 1971 onwards. We impute the missing data for 1963-70 by using each sector's growth rate of real value added between 1971 and 2000. The resulting sectoral real value added time-series are used to compute labor productivity by sector for Korea and the OECD, as we describe below. We compute the GDP shares of sectors presented in Section 2 using the WDI's current dollar sectoral and aggregate GDP data ${ }^{7}$.

We construct aggregate real GDP measured in 1995 constant US dollars for Korea and OECD member countries using aggregate real value added at factor cost, in current and constant 2000 US dollars, drawn from the WDI online database. For each country, we first compute a value added deflator with 2000 as the base year, dividing current dollar by constant 2000 US dollar value added, and then shift the base year from 2000 to 1995. We apply the resulting deflator series allows us to compute gross value added in constant 1995 US dollars. This ensures compatibility of aggregate real value added with our measures of sectoral real value added which are measured in constant 1995 US dollars. Real GDP per worker for Korea is then computed by dividing aggregate real value added by total Korean employment. Real GDP per worker for the OECD is constructed as a weighted average of individual countries' aggregate real gross value added per worker, where the weights are the share of that country's employment in total OECD employment. Figure 2 displays the ratio of Korean to OECD real GDP per worker. Construction of the employment data is discussed next.

Employment: The Groningen Growth and Development Centre (GDDC) 10 sector database provides data on employment in each of 10 sectors in Korea. We aggregate employment in these ten

\footnotetext{
${ }^{7}$ Kuznets (1966) found that nominal and real GDP shares of sectors exhibited very similar qualitative behavior. However, Herrendorf, Rogerson and Valentinyi (2014) found that while this was true of almost every country, Korea's nominal manufacturing GDP share exhibited a hump-shape like the employment share of the sector, while the real GDP share of the sector continued to grow beyond the nominal share's peak, implying a substantial decline in the relative price of manufacturing goods. Despite our broader sectoral definition, the nominal GDP share of industry in Figure 3 also displays a hump shape, albeit a muted one relative to the employment share of the sector. We elect to present the nominal GDP shares of sectors, and focus in any case on matching the employment shares of sectors in our analysis.
} 
sectors into employment in agriculture, industry and services using the ISIC sectoral classifications described above, and total employment is simply the sum of employment across all sectors. The sectoral employment shares for Korea, which we display in Figure 3 and are the targets for our model, are derived by dividing employment in each of the three sectors by total employment for the period 1963-2000.

Data on employment by sector for the OECD are constructed from the OECD Annual Labor Force Statistics database which reports civilian employment in each sector by member country for the period 1970 onwards. We first aggregate sectoral employment for each country using the ISIC sectoral classifications described above. We then impute missing observations for sectoral employment in every country for the years 1963-70 by using the growth rate of employment in each sector for each country between 1971 and 2000. Finally, OECD employment by sector is obtained by summing employment across all member countries for each sector. Total OECD employment is just the sum of sectoral employment numbers.

Value Added Trade: To derive the value added trade flows between Korea and OECD by sector we use two data sources. The first is Robert Feenstra's Trade Data, SITC Revision 2, from which we obtain the bilateral gross imports and exports of Korea with respect to OECD countries for agriculture and industry for our entire sample period. Agriculture is defined as the sum of SITC product categories 0, 1, 2, and 4, minus 27 and 28. Industry is the sum of Fuels and Mining - SITC categories 3 plus 27, 28, and 68, Manufacturing - SITC categories 5,6,7, and 8 minus 68, and all other SITC codes. Gross imports of Korea from the OECD are constructed as the sum of Korea's imports from each country in our list of OECD member countries ${ }^{8}$. Similarly, gross exports of Korea to the OECD are constructed by summing Korea's exports to each member country in the OECD. The second data source is Johnson and Noguera (2014) "A Portrait of Trade in Value Added over Four Decades" ${ }^{9}$, which provides information on bilateral value added and gross trade for Korea with 41 trade partners, including some OECD countries and other major emerging economies, from 1971 to 2009. However, the set of OECD partner countries of Korea is smaller in the Johnson and Noguera (2014) data than in the Feenstra data so we do not directly use the value added trade flows of Johnson and Noguera (2014). Instead, we impute bilateral value added trade flows between Korea and our broader set of OECD countries as follows.

\footnotetext{
${ }^{8}$ The OECD includes Australia, Austria, Belgium, Canada, Denmark, Finland, France, Germany, Greece, Italy, Japan, Netherlands, Norway, Portugal, Spain, Sweden, the United Kingdom and United States.

${ }^{9}$ We are extremely thankful to Robert Johnson for providing the data on South Korea.
} 
First, for agriculture and industry separately, we derive a ratio of value added to gross bilateral trade flows using the Johnson and Noguera (2014) data. Johnson and Noguera provide value added and gross trade flows for agriculture, non-manufacturing industrial production, manufacturing industrial production, and services, so we aggregate trade for the two industrial production sectors to be consistent with our definition of sectors. For each sector and year, we compute value added exports and imports, and gross exports and imports, between Korea and "the OECD" by summing each trade flow measure across the OECD member countries that are included in the data set. Imports of Korea from the OECD are obtained as the sum of OECD member countries' exports to Korea, since the original data set only provides value added exports of countries. Then, for each sector and each year for the period 1971 to 2000, we take the ratio of total value added exports from Korea to "the OECD" to total gross exports, and total value added imports of Korea from "the OECD" to total gross imports. While a crude approximation, we assume that from 1963 to 1970 the value added to gross export and import ratios take their 1971 values. Finally, we estimate value added exports from Korea to our more comprehensive set of OECD member countries for each sector, and for the sample period 1963-2000, by multiplying sector-specific value added-to-gross export ratios by Korea's gross exports to the OECD in that sector computed using Feenstra's data. An identical procedure, multiplying sector-specific value added-to-gross imports ratios and the gross imports of Korea from the OECD that we computed using Feenstra's data yields value added imports of Korea from the OECD.

\subsection{Data Inputs for the Model}

There are three time-series that we directly input to our benchmark model of Korea's trade policy reform and structural change.

Labor Productivity by Sector: We divide real value added in each sector by employment in that sector for Korea for 1963-2000 to get a time series of sectoral labor productivity. Real value added per worker by sector in the OECD is computed as the weighted average of member countries' real value added per worker in that sector, where the weights are the share of a member country's sectoral employment in total OECD employment in that sector.

Tariff Rates: Complete annual average tariff rate estimates by sector are unavailable for the 1963-2000 sample period for Korea. Furthermore, tariff rates are usually available for the manufacturing sector and not the whole industrial sector. As a result, we use manufacturing sector tariff rates as a proxy for industry's tariffs. There are three studies that provide tariff rates for both 
manufactured and agricultural products; Nam (1980) for 1968- which also reports an aggregate tariff rate for 1968, Kim (1996) for the period 1983-94, and the Bank of Korea for the period 1994-2000. By splicing the Kim (1996) and Bank of Korea data, we have complete time series of tariff rates for both sectors from 1983-2000. For the period 1963-82 we have to combine data from different sources, and use an extrapolation methodology to construct sectoral tariff rates (time series are presented in Table 1), which we now explain.

Industrial Tariff Rates: Nam (1980) is the only source that provides estimates of tariff rates in both sectors for any year prior to 1983, and hence the 1968 estimates he provides are the only source of information on the relative size of tariff rates across sectors from 1963 through 1982 - information that is invaluable for our analysis. Lee (1995), provides an estimated average manufacturing sector tariff rate for each of the following sub-periods: 1962-67, 1968-72, 1973-76 and 1979-83. We compute the factors by which these average manufacturing tariff rates changed between sub-periods, and apply these "growth factors" to extrapolate Nam (1980)'s 1968 manufacturing tariff rate estimate - backwards and forwards - to construct data for the missing years. For example, using Lee (1995)'s average tariff rates for 1962-67 and 1968-72, we compute the factor by which the average manufacturing tariff rate changed between the two sub-periods. We then apply this growth factor to Nam (1980)'s 1968 value of the manufacturing tariff rate to extrapolate it backward. Since Lee (1995)'s data are averages over the sub-periods, as a simplification we assume that the extrapolated value applies to each year of the sub-period 1963-67, and that Nam (1980)'s 1968 value applies to each year during 1968-72. We use the same methodology to obtain the growth factor between 1968-72 and 1973-76 and then extrapolate Nam (1980)'s data forward for 1973-76. Again, the extrapolated value is assumed to apply to each year during 1973-76. Finally, we calculate the growth factor between 1973-76 and 1979-83 and use it to extrapolate the 1973 tariff rate forward to derive the tariff rate for the 1979-83 period. Since Lee (1995) does not provide any estimates for 1977 and 1978, we are forced to assume that the extrapolated value for 1973-76 applies to these two years as well.

Agricultural Tariff Rates: Unfortunately, there is no other source of earlier agricultural tariff rates from which we could extrapolate that for 1968 reported by Nam (1980). However, Collins and Park (1989a) present data on simple average tariff rates for South Korea for the period 19521984. Though not a continuous time series, estimates for 1962, 1968, 1973, and 1979 are provided. We construct agricultural tariff rates by (a) assuming that the aggregate tariff rate in each period 
is a simple average of the manufacturing and agricultural tariff rate, (b) extrapolating the 1968 aggregate tariff rate for Korea reported by Nam (1980) using "growth factors" based on the data from Collins and Park (1989a), and (c) inferring agricultural tariff rates implied by assumption (a). We compute a growth factor between 1962 and 1968 based on the Collins and Park (1989a) estimates, and then use it to extrapolate backward the 1968 aggregate tariff rate from Nam (1980), yielding an estimate for the 1962 aggregate tariff rate. We assume this extrapolated aggregate tariff rate for the economy applies to every year from 1963 to 1967. Repeating this methodology for periods 1968 to 1973 and 1973 to 1979 gives us the aggregate tariff rate in 1973 and in 1979. The 1973 estimate is applied to each year during the period 1973 to 1978 and the 1979 estimate is applied to each year during the period 1979 to 1983. Lastly, Nam's (1980) aggregate tariff rate for 1968 is assumed to apply to every year from 1968 to 1972. We then infer the tariff rate for agriculture for every year from 1963 to 1982 from our estimated industrial and aggregate tariff series.

We proxy average tariff rates by sector imposed by the OECD on Korean imports by the simple average effective import tariff rates by sector imposed by the US on Korean imports. These data are obtained from the World Integrated Trade Solution (WITS) - Trade Analysis and Information System (TRAINS) - database of the World Bank. The data are only available from 1988 through 2010, so we must construct tariff rates for the period 1963 through 1987 . We compute a constant annual growth rate, calculated for the 1989-2010 period, and then extrapolate backwards to derive annual tariff rates on agricultural (defined as food plus agricultural raw materials) and manufacturing imports for the period 1963-1987.

Our estimated agricultural and industrial tariff rates for Korea and the OECD are presented in Table 1.

\section{Table 1 goes here}

Subsidy Rates: To measure export subsidy rates by sector in Korea, we use the industrial gross subsidy rate calculated from 1963 through 1980 by Collins and Park (1989b), net of tariff exemptions. Industrial export subsidies include direct cash subsidies, export dollar premiums, direct tax reductions, preferential interest rates, indirect tax exemptions, and tariff exemptions on intermediate and capital goods. We exclude tariff exemptions because our model features value added production without intermediate inputs. The Collins and Park series suffers from missing observations, after 1980, for indirect tax exemptions; however, it is widely believed that quanti- 
tatively significant subsidies ended in Korea during the 1980s, the Collins and Park net subsidy estimates are zero after 1980, and Nam (1995) argues that all export subsidies were eliminated by 1982. Unfortunately, we are unaware of any estimates of average agricultural subsidy rates although they were reputedly large, as Teignier (2014) reports, and so we assume in our benchmark calibration that agricultural subsidies are awarded at the same rate as in industry. In the absence of evidence to the contrary, we assume that OECD subsidies offered for exports to Korea are zero in both sectors throughout the sample period. It is worth noting that, since subsidies awarded to agriculture and industry are the same in Korea and they are also both zero in the OECD, in our benchmark calibration subsidy rates do not distort the pattern of comparative advantage. We present the original subsidy rates in Table 2. The last column of this Table displays the measure of subsidies - gross subsidies net of tariff exemptions - that we use in our calibration.

\section{Table 2 goes here}

\subsection{Preference Parameters}

The curvature parameter in household preferences, $\psi$, determines the representative household's elasticity of inter-temporal substitution. We follow Backus, Kehoe and Kydland (1992) and set, $\psi=-1$; hence, the elasticity of inter-temporal substitution is $\frac{1}{1-\psi}=0.5$. The weight on consumption of the sector $k$ good in the consumption aggregate, $\xi_{k}$, and the elasticity of substitution between the three type of goods, $\omega$, are taken from Herrendorf, Rogerson and Valentinyi (2013) and are computed from final consumption expenditure data. The values we use are $\xi_{A}=0.02, \xi_{I}=$ $0.17, \xi_{S}=0.81$. In addition, we let $\omega=-0.175$ implying that the three types of final good are complements in preferences.

Herrendorf, Rogerson and Valentinyi (2013) emphasize the need for consistency of the production and consumption sides of multi-sector models of structural change. In many models, such as ours, the production technology includes no explicit input-output structure and all output (of varieties) is characterized as value added. Consequently, the authors argue, the sector $k$ consumption argument of the utility function is correctly interpreted as consumption of the value added produced by industry $k$, rather than as final consumption expenditure on commodity $k$ (or on the commodity primarily produced by industry $k$ ). Indeed, in our environment, market clearing conditions for varieties and for final goods imply that the value added produced by each sector's variety firm is what is consumed by households at home and abroad. In such a model, Herrendorf, Rogerson and Valentinyi (2013) reason that extracting the value added component of each industry 
from final consumption expenditure data is needed to measure value added consumption by sector and to calibrate appropriately the parameters of the utility function. The extraction of value added consumption thus reconciles empirically the production and consumption sides of a value added economy, and the authors develop a method for doing so. Ideally, therefore, we would use utility function parameters estimated from extracted consumption value added data rather than parameters estimated using final consumption expenditure data. However, in our model household consumption explicitly includes imported value added through the Armington aggregator. An important assumption made by Herrendorf, Rogerson and Valentinyi (2013) in extracting consumption value added from final consumption data is that the input requirements for home and foreign produced commodities are the same, an assumption which is violated by the country-specific labor productivities of our model and in our data. Rather than attempt to develop a new method for estimating consumption value added in an open economy environment, which is beyond the scope of this paper, we experimented by using an average of the final expenditure and value added consumption weights computed by Herrendorf, Rogerson and Valentinyi (2013). Our results were qualitatively identical and quantitatively very similar and we do not report them here.

Finally, the subsistence level of consumption of agricultural goods, $\bar{A}$, is assumed to be the same for South Korea and the OECD. It is chosen to match the 1963 employment share of agriculture in South Korea, which is 0.63 , and in our benchmark calibration $\bar{A}$ equals 544.73 . This implies that in 1963 the subsistence level of consumption of agricultural goods accounted for 76 percent of total final consumption expenditure and 98.5 percent of consumption expenditure on agricultural goods in Korea.

\subsection{Trade Parameters}

In our model, the Armington weights, $\mu_{i}^{k}$, are assumed to capture all primitive preference and technological factors which would affect expenditure by final good producers on domestic varieties of goods relative to imported varieties, after controlling for the marginal costs of production in the two countries, and for tariffs and subsidies. Hence, these weights include non-tariff trade barriers such as import quotas. We manipulate (3.8) and (3.9) to get the following expressions:

$$
\mu_{i}^{k}=\left[\frac{p_{i, t}^{k} y_{i, i, t}^{k}}{P_{i, t}^{k} Y_{i, t}^{k}}\right]^{1-\rho}\left[\frac{p_{i, t}^{k}}{P_{i, t}^{k}}\right]^{\rho}
$$




$$
1-\mu_{i}^{k}=\left[\frac{\frac{\left(1+\tau_{i, j, t}^{k}\right)}{\left(1+s_{j, i, t}^{k}\right.} p_{j, t}^{k} y_{i, j, t}^{k}}{P_{i, t}^{k} Y_{i, t}^{k}}\right]^{1-\rho}\left[\frac{\frac{\left(1+\tau_{i, j, t}^{k}\right)}{\left(1+s_{j, i, t}^{k}\right)} p_{j, t}^{k}}{P_{i, t}^{k}}\right]^{\rho} .
$$

We then calibrate the values of $\mu_{i}^{k}$ and $\left(1-\mu_{i}^{k}\right)$ using data to estimate the right hand sides of (4.1) and (4.2) for each sector $k=\{A, I\}$ and country. We obtain independent estimates for the value of $\mu_{i}^{k}$ and $1-\mu_{i}^{k}$ period by period which we denote by $\mu_{i, t}^{k}$ and $1-\mu_{i, t}^{k}$, and apply the following normalizations in each period to ensure that the values of the weights sum to unity, $\widetilde{\mu_{i, t}^{k}}=\left[\frac{\mu_{i, t}^{k}}{\mu_{i, t}^{k}+\left(1-\mu_{i, t}^{k}\right)}\right]$ and $1-\widetilde{\mu_{i, t}^{k}}=\left[\frac{1-\mu_{i, t}^{k}}{\mu_{i, t}^{k}+\left(1-\mu_{i, t}^{k}\right)}\right]$. Annual data measuring the variables on the right hand side of equations 4.1 and 4.2 go back to 1971 . Normalized parameter values for 19631970 are computed by extrapolating backwards from 1971 using the growth rates of the estimated normalized parameter values for 1971-2000. The final calibrated values are full sample averages of the normalized estimates for each sector and country.

Specifically, to compute spending on the domestic variety in the numerator of the first term of (4.1), we subtract our constructed sectoral nominal value added exports from that sector's total nominal value added. For both Korea and the OECD, sectoral nominal value added data sources are the same as those we used to compute labor productivities. Total spending on the two varieties, in the denominator of the first term on the right hand side of (4.1), is constructed as the sum of value added and spending on value added imports, less value added exports, in each sector. The second term on the right hand side of equation (4.1) is the producer price of the domestic variety relative to the consumer price index of sector $k$ in country $i$. To measure this, we divide Korean producer price indexes by sector obtained from the Bank of Korea, and US producer price indexes by sector from the Bureau of Labor Statistics, by consumer price indexes by sector for Korea and the US respectively. The latter are constructed using data from the Bank of Korea and the Bureau of Economic Analysis, following a methodology described in Herrendorf, Rogerson and Valentinyi (2013).

To compute the share of spending on the foreign variety of sector $k$ in the first term of (4.2), we use our constructed data on value added imports by sector, and the same measure of total spending by sector for the denominator as we constructed for (4.1). The second term of (4.2) reflects the price of the imported variety relative to the consumer price index of sector $k$ in country $i$. For Korea we use import price index data by sector from the Bank of Korea. For the OECD, we proxy the price of the Korean variety imported by the export price index data by sector from the Bank of Korea. Consumer prices are measured as described for (4.1). Our measures of value added 
imports yield good estimates of the numerator in the first term of (4.2). The import price data that we use to calibrate the numerator of the second term, by contrast, are measured inclusive of "cost, insurance and freight" (CIF), and presumably any export subsidies, but do not reflect the value of tariffs. We therefore include our estimated tariff series in calibrating the numerator in the second component of (4.2). Since data on non-tariff trade barriers by sector are not available, our measures of $\mu_{i}^{k}$ capture these barriers such as import quantity controls.

Our calibration of trade costs, captured by the Armington weights, uses not only data on trade flows but also data on prices of domestically and imported varieties. In contrast, Sposi (2014) and Uy, Yi and Zhang (2013) rely solely on trade flows to impute the iceberg trade costs in their models. Both, Sposi (2014) and Uy, Yi and Zhang (2013) match trade flows to compute trade barriers. Thus, we bring to bear more information in inferring trade costs compared to other recent open economy models of structural change. Waugh (2010) and Anderson and Wincoop (2003) argue that inclusion of price data matters for the magnitude of as well as the asymmetry of bilateral trade costs.

The resulting values of the Armington weights by sector are shown in Table 3.

\section{Table 3 goes here}

A key parameter of the model is $\rho$ which controls the elasticity of substitution between home

and foreign goods, $\frac{1}{1-\rho}$. Ruhl (2008) states that international real business cycle (IRBC) models need small values of this elasticity to generate the volatility of the terms-of-trade and the negative correlation between the terms-of-trade and the trade balance that are found in the data. For example, Backus, Kehoe and Kydland (1994) and Zimmermann (1997) use an elasticity of 1.50. By contrast, general equilibrium models such as Yi (2003) shows an elasticity of 12 or more is needed to explain the growth in trade volumes that results from tariff reductions. Eaton and Kortum (2002) find a range of 3.6 to 12.8. However, Simonovska and Waugh (2014) show that the small sample size of the price data used in Eaton and Kortum (2002) strategy results in a small sample bias. Correcting for this bias, they find a lower estimate of 4. Giri (2012) also shows that, within the Eaton and Kortum framework, the elasticity estimate needed to match the cross-country dispersion in prices of individual goods ranges from 1.72 to 5.5. In line with most recent estimates, we choose a value of 4 for the elasticity which implies $\rho=0.75$. 


\section{Results}

\subsection{The Benchmark Open Economy Model}

The first row of Figure 4 plots employment shares by sector implied for Korea for the period 1963 through 2000 by a benchmark economy calibrated as we describe in Section 4, with our estimated time-series of tariffs, subsidies, and labor productivity as inputs for the simulation. The figure compares these model implied sector shares to those observed in the data.

Qualitatively, the model captures Korea's structural change over the sample period. Quantitatively, the model matches closely the magnitude of decline in the employment share of agriculture, implying a slightly larger decline than actually observed, from 0.63 in 1963 to 0.06 in 2000, or 109\% of the actual decline. While the model produces a hump-shape in the employment share of industry, it mis-times the peak. While the initial, 1963 industrial employment share implied by the model is about 0.20 , significantly higher than the 0.11 share in the data, the model implies an immediate decrease to 0.12 in 1965 and 0.14 in 1966, values almost identical to the actual shares of 0.13 in 1965 and 0.14 in 1966. Industry's employment share then increases to a peak of 0.30 in 1980, tracking the data closely for these years, subsequently declining to a low of 0.23 in 1983, flattening and fluctuating a little, and finally reaching 0.26 in 2000. In the data, by contrast, industry's share of employment peaked a decade later and at a higher value, in 1991 at 0.36, and then slowly declined to a low of 0.29 in 2000. Because the model implies a 1963 industrial employment share that is too high, it can account for only 10 percentage points, or 40 percent, of the 25 percentage point increase observed in the data from 1963 to its peak. However, since the model implies an immediate decline in industry's employment share to 0.14 by 1966, it captures 78 percent of the increase observed in the data from 1965 to the peak. In addition, comparing the magnitudes of decline from the peak to subsequent low - the downward portion of the industry's employment share "hump" - the model captures 7 percentage points, or 87.5 percent, of the 8 percentage point decline in the data.

The benchmark model implies a lower value of services' 1963 share of employment in 1963 at 0.17 compared to 0.25 in the data - the mirror image of the model implied higher value of industry's 1963 employment share. However, the model's implied share of services for 1964 is 0.25 , only 2 percentage points shy of the data, and then increases almost exactly with the data until 1971 when both are 0.34. In 1972, a temporary decline in services' employment share (and increase in agriculture's) occurs in the data which persists through 1976 and is not captured by the model. Subsequently, however, services' employment share in the data recovers and the actual and model 
implied share resume increasing at roughly equal rates. As a result, although from 1963 through 2000 the 51 percentage point increase in services' employment share in the model is more than 140 percent of the 36 percentage point increase actually observed, from 1976 onwards the model accounts for 87 percent of the 32 percentage point increase seen in the data.

The benchmark economy tracks qualitatively and quantitatively the trends in all three employment shares, but has inaccurate implications for 1963 industry and service sector shares and hence their total sample period changes. The 1963 industrial sector employment share implied by the model is higher than its data counterpart not in only the benchmark but also every other open economy variant of the model that we simulate, including one in which Korean trade policies are counterfactually set equal to zero. By contrast, a closed economy counter-factual experiment, in which we recalibrate $\bar{A}$ to match the 1963 employment share of agriculture, accurately produces the initial shares on industry and services. This shortcoming of the open economy model is attributable to the initial pattern of trade it implies, which excessively favors Korean industry and exaggerates Korea's 1963 industrial sector exports, as we describe below. Additionally, the benchmark model's suggested decrease in industry's employment share in 1964 and 1965 is not seen in experiments that we describe below in which Korean tariffs and subsidies are held constant counterfactually at their 1963 levels. We infer that this results from a sharp decline in subsidies from 1963 to 1965, as can be seen in Table 2 .

\section{Figure 4 goes here}

Table 4 records the values of some goodness of fit summary statistics ${ }^{10}$. The statistics in the first two rows of the table quantify the distance between the model implied and actual time series of the employment share of each sector according to two standard criteria; the sum of squared errors (SSE) and the root mean squared error statistic (RMSE) respectively. We also present the summation of SSE's over sectors, the "total" SSE, and the associated "total" RMSE for the model. While there is no absolute criterion for a "good" SSE or RMSE, these statistics are useful for comparing the performance of our benchmark model to counter-factual models, and even to other models of structural change in Korea. The statistics presented in the third row of the table are the

\footnotetext{
${ }^{10}$ The sum of squared errors statistic, for outcome variable $X_{t}$, is defined as $S S E=\sum_{t=1}^{T}\left(X_{t}-\hat{X}_{t}\right)^{2}$ where $T$ is the number of years in the sample, $X_{t}$ is the data value at date $t$, and $\hat{X}_{t}$ is the model implied value for $X_{t}$. This is computed by sector, and the "total" statistic is just the sum of these across sectors. The root mean squared error statistic is $R M S E=\sqrt{\frac{S S E}{T}}$. The correlation statistic is defined as $C O R R=\sum_{t=1}^{T}\left(X_{t}-\mu_{x}\right)\left(\hat{X}_{t}-\mu_{\hat{X}}\right) /(T-1) / \sqrt{\left(\operatorname{var}\left(X_{t}\right) \operatorname{var}\left(\hat{X}_{t}\right)\right)}$ where $\mu_{j}$ denotes the sample mean of variable $j$, and $\operatorname{var}(j)$ denotes the sample variance.
} 
sample correlation coefficients between the model implied time series for the employment share of a sector and that in the data, and measure the similarity of annual fluctuations in the two. The sample correlations are all very large and positive. They are higher for agriculture and services than for industry reflecting the counterfactual decline in industry's share from 1963 through 1965 and mis-timing of industry's employment share peak. The SSE and RMSE are smallest for agriculture and largest for services. Our RMSE statistics are quantitatively comparable to those of Uy, Yi and Zhang (2013), who develop a similar model measuring structural change in Korea. Our benchmark model suggests an RMSE for the employment share of Korean agriculture of 0.04, somewhat lower than the 0.059 they find. However, our model implied RMSE statistics for industry and services of 0.061 and 0.084 respectively, somewhat higher than the 0.037 and 0.06 their model generates.

\section{Table 4 goes here}

The second and third rows of Figure 4 show the benchmark model's performance in matching Korean total value added imports and exports, and value added imports and exports by sector, as a fraction of GDP. Value added exports to GDP for each sector are the "foreign effect" for the Korean employment and GDP share of that sector defined in Section 3. Overall, the benchmark model implies quite realistic magnitudes of value added trade, matching very closely total imports to GDP, and while it over-estimates total exports in GDP until about 1973 subsequently tracks the magnitude closely on average. The model is much less successful in tracking trade by sector. While it matches the magnitude of value added agricultural exports to GDP in the early years, and the magnitude of industrial value added exports to GDP in the later years of the sample, it implies substantially higher value added Korean imports to GDP in agriculture and lower imports to GDP in industry. The time series fluctuations in the benchmark model's implied industry's exports to GDP ratio mirror, although they magnify, the fluctuations in its implied industrial employment share in the benchmark model, and this feature is also seen in the data. The calibrated benchmark model correctly suggests that the "foreign effect" strongly influences fluctuations in the employment share of industrial goods in Korea. However, it implies an excessive initial value for the foreign effect of industry, and this results in a 1963 employment share of the sector that is too high.

The value added trade balances of agriculture and industry for our benchmark model, evaluated at world prices, are shown in the last row of Figure 4. At world prices, trade must be balanced. However, the model implies a pattern of value added trade that favors Korean industry and OECD agriculture throughout the sample. Korea runs value added trade deficits in agriculture throughout 
the sample, and exactly offsetting industrial sector surpluses. As Section 3 demonstrates, in the model the higher are sectoral net exports, the more labor specializes in that sector, and the larger is its employment share so the implied trade pattern supports industrialization and the decline of agriculture. In the data, and as can be inferred from the sectoral export and import to GDP graphs in Figure 4, Korean agriculture actually ran value added trade surpluses with the OECD from 1972 until 1995. Conversely, Korean industry's OECD value added trade was systematically in deficit until 1983, although deficits declined over time, and surpluses emerged. Our balanced trade assumption is imprecise period by period, but not too far from the data on average; Korea ran a small value added trade deficit on the sum of agricultural and industrial goods trade over our sample period, amounting to about 1 percent of GDP.

The relative magnitudes of exports and imports by sector and the associated pattern of trade between Korea and the OECD are determined by several factors. Sectoral productivity differentials across countries measure comparative cost advantage and, adjusted for tariffs and subsidies, determine the scope for international specialization. The importance of agricultural subsistence consumption in Korea relative to the OECD, and the Armington weights and unobserved barriers to trade that they measure also affect the pattern of trade and specialization, however. Relatively low Korean income early in the sample means that her consumption expenditure is relatively heavily weighted towards agriculture, encouraging agricultural imports. The OECD exhibits higher home bias for agricultural than for industrial goods while Korea has higher home bias for industrial than for agricultural goods, a pattern that encourages Korean specialization in industry and OECD specialization in agriculture. These factors dominate the pattern of trade implied by the model, including in 1963 despite the fact that Korean agriculture is relatively heavily protected by Korean tariffs and exhibits relatively high labor productivity at this date. Why does the model overestimate the level of net imports in agriculture?

Three factors contribute. The first, barriers to Korean agricultural imports may be too low in the calibrated model compared to the data. This is plausible because data on Korean tariff rates are available only for the manufacturing sector and for the economy as a whole, and we infer agricultural tariff rates by assuming that the aggregate tariff rate is a simple average of manufacturing and agricultural tariff rates. This could introduce measurement error, and potential underestimation of agricultural tariff rates. The second, given trade barriers, the demand for agricultural imports is too high due to higher final consumption expenditure on agricultural goods in the calibrated model 
than in the data. This could occur if $\bar{A}$, which is picked to match the share of agriculture in 1963 employment, represents too high a level of subsistence consumption relative to the data. Third, our strategy of inputting time series data for policy barriers for trade, calibrating the Armington weights to match import expenditure share and relative price data, highly disciplines the model ties our hands - compared to a strategy of calibrating generic iceberg costs to match bilateral trade by sector period by period. For example, according to (4.1) and (4.2), the Armington weight on a variety is a weighted average of (i) its share in total expenditure on that sector's final good, and (ii) its price relative to the price index of the sector's composite final good, with the weights being governed by the elasticity of substitution between domestic and foreign varieties. We input data on (i) and (ii), and an independent estimate of rho, to calibrate these weights. Since (4.2), must hold in equilibrium, the calibrated model's overestimation of Korean agricultural imports implies underestimation of the relative price of the imported OECD agricultural variety. The relative price of imported OECD agricultural variety equals the product of (a) the ratio of Korean to OECD agricultural productivity, and (b) the ratio of the OECD to the Korean wage (see (3.15) and (3.16) where (a) is a data input in our calibration while (b) is endogenous. Our strategy for calibrating the Armington weights means that measurement error in productivities, or inaccuracy in the model's prediction for wages, implies counter-factual sectoral trade volumes.

Finally, because Korea has dramatically lower degrees of home bias than does the OECD in all sectors, large incipient Korean trade deficits, and especially agricultural trade deficits result. As equation (3.16) shows, for exogenous policies, productivities, and Armington weights, a decline in Korea's relative wage rate is needed to stimulate Korean exports and reduce Korean imports. This adjustment occurs naturally, due to relatively low world demand for Korean varieties of both agriculture and industry, which depresses Korea's relative labor demand and wage. This results in relatively low producer prices of Korean varieties of both agriculture and industry, causing expenditure switching by OECD final good producers into Korean exports, especially Korean industrial exports because OECD home bias is lower in industry. It also results in lower Korean wage income, reducing Korean expenditure on imports, but especially industrial imports, since lower income biases consumption expenditure towards agricultural products. To balance trade and eliminate the large aggregate, and especially agricultural trade deficit, Korea's net (industrial) exports must rise substantially requiring a large reduction in Korean wages and producer prices. 


\subsection{Closed Economy Experiment}

Closing the economy and comparing it with our benchmark open economy is a measure of how important openness to trade and measured trade policies are for Korean structural transformation. This exercise enables us to examine the consequences for structural change when there are exogenous changes only in the growth of sectoral labor productivity, which have no implications for comparative advantage in a closed economy. To close the economy, we set $\mu_{K O R}^{k}=\mu_{O E C D}^{k}=1$ for all $k$, effectively assuming that trade costs are prohibitively high. In terms of our model, only the "domestic effect" of each sector matters for a sector's employment share. The consequences of differential productivity growth across sectors for domestic relative producer prices, and for income effects acting on domestic consumption expenditure shares, are the sole sources of structural change.

This counterfactual model fails to match the employment share data in all three sectors by a wide margin, as shown in Figure 5. In part, this reflects the fact that the preference parameter $\bar{A}$ is maintained at the value required to match agriculture's initial employment share in the benchmark open economy, as we treat its benchmark calibrated value as a deep parameter in all of our counterfactual exercises. The closed economy model vastly under-estimates the initial employment share in agriculture, and consequently the initial shares of industry and services are both too high. Furthermore, labor gradually moves out of agriculture directly into the service sector, allowing for essentially no industrialization. An implication of these results is that domestic sectoral productivity growth differentials, and the domestic relative price and consumption expenditure share changes they engender, are insufficiently large to generate industrialization or de-industrialization. If income were sufficiently low that expenditure on subsistence agricultural consumption comprised a large fraction of total expenditure, then strong income effects arising from economic growth would cause the consumption expenditure and employment shares of industry and services to grow over time as agriculture shrank. However, in 1963, the value of subsistence consumption is only 21 percent of total income in the closed economy as compared to 76 percent in the open economy model. Income is higher in the closed than open economy because Korean labor demand and wages are solely determined by domestic consumer demand for Korean varieties, rather than by the relatively low global demand produced by low Korean home bias and very high OECD home bias which necessitate a decline in Korean wages to balance trade. Hence, domestic sectoral productivity growth differences between agriculture and services generate the only action; a movement of resources from 
agriculture to services ${ }^{11}$.

The bottom right graph in Figure 5 shows the growth rate of Korean GDP per capita as implied by the benchmark and closed economy model relative to the data. Allowing for international trade dramatically improves the ability of the model to match real income growth. Between 1963 and 2000, real GDP per capita measured in 1995 dollars actually grew from 4,037 dollars to 30,179 dollars, or by a factor of 7.5. In the benchmark economy, real GDP per capita grew by a factor of 4.24 , which accounts for 62 percent of the growth seen in the data, while in the closed economy model real GDP per capita grew by a factor of 2.63, which accounts for just 47 percent of this growth.

Table 4 shows that the RMSEs for industry and services in the closed economy rise by 82 percent and 219 percent respectively, relative to the benchmark economy. For agriculture, the RMSE is more than 300 percent higher than in the benchmark. The total RMSE in the closed economy is 226 percent higher than that in the open economy model ${ }^{12}$.

\section{Figure 5 goes here}

\subsection{Trade Policy Counterfactuals}

We conduct several counterfactual policy experiments to clarify the role of Korean tariff and subsidy policies, and their liberalization, for structural change.

\subsubsection{The Role of Korea's Tariff Policy}

Figure 6 depicts the effects of abstracting from all changes in tariff rates that occured after 1963. Tariff rates are counterfactually held at their 1963 levels for the entire sample period. Since tariff rates in the data and benchmark model are unchanged between 1963 and 1967, the effects of this experiment emerge only after 1967.

Starting with the first row of Figure 6, in the data and benchmark model, agricultural sector tariff rates decline systematically throughout the sample period except for a single year increase in 1983. Hence, maintaining 1963 tariffs results in a systematically higher relative price of the OECD imported variety of agriculture. Final good producers in Korea therefore switch to the cheaper

\footnotetext{
${ }^{11}$ When $\bar{A}$ is re-calibrated in the closed economy to match the initial employment share of agriculture, the expenditure on subsistence consumption is $62 \%$ of 1963 income. A larger income effect results in significantly more growth in industry's employment share than in the version where $\bar{A}$ is not re-calibrated. Nonetheless, it can generate only 32 percent of the maximum increase in industry's employment share from 1963 to 1990 - 8 percentage points of 25 in the data - and none of the subsequent decrease.

${ }^{12}$ In the version of the closed economy model where $\bar{A}$ is re-calibrated, the RMSE for industry and services is 127 percent and 42 percent higher than in the benchmark open economy, respectively. For agriculture the RMSE declines by about 26 percent compared to the benchmark. Despite this recalibration, compared to the benchmark model the total RMSE is more than 60 percent higher, largely due to the tepid industrialization implied by the model.
} 
domestic variety, and agricultural imports decline. By contrast, tariffs in Korea's industrial sector are higher between 1968 and 1978 than they are in 1963. Counterfactually maintaining the 1963 industrial tariff rate therefore reduces the price of the imported OECD variety of industry relative to the Korean variety during this period. In 1979, the industrial tariff rate in the data and benchmark model finally falls below the 1963 rate and the relative price of industrial imports is higher in the counterfactual model. Expenditure switching by Korean final good producers increases Korean industrial imports from 1968 through 1978, and decreases them after 1978. However, total imports are lower in the counterfactual relative to the benchmark model at every date.

Lower total imports imply an incipient Korean trade surplus and Korean exports must decline and/or the fall in imports attenuated for trade to be balanced. As we have described, relative wages drive this adjustment mechanism, as the shift in Korean, and hence world, demand from OECD to Korean varieties resulting from counterfactually high Korean tariffs increases Korean labor demand, wages, and per capita income. At the same time, lower Korean demand for OECD varieties reduces OECD production, labor demand, wages, and per capita GDP. The increase in relative Korean income is shown in Figure 6. Korean expenditure rises, mitigating the decline in imports, and OECD expenditure falls reducing Korean exports. In addition, a higher relative Korean wage rate increases the producer prices of Korean relative to OECD varieties and shifts world demand for Korean and OECD varieties in the opposing direction than maintaining 1963 Korean tariff rates does, causing expenditure switching by final good producers in favor of OECD varieties. Korea's exports decline, and imports rise. Together, these income and relative price effects counter Korea's incipient trade surplus.

Overall, Korean imports, exports, and total trade fall relative to the benchmark economy. In addition, industry's net exports and agriculture's net imports decline, although insufficiently to alter the benchmark pattern of trade. This "compression" of the pattern of trade is attributable to three factors. First, high 1963 agricultural relative to industrial tariffs compared to those in the benchmark economy disproportionately reduce Korea's agricultural imports. Second, maintaining 1963 tariffs results in a higher relative price of the OECD imported variety for both sectors, but the smaller Korean agricultural home bias compared to industry amplifies the decline in agricultural imports. Additionally, Korean industrial exports decline disproportionately more than agricultural exports because OECD final good producers' relatively low home bias in industry amplifies their response to an increase in the producer price of Korean varieties during trade balance adjustment. 
Third, higher Korean wage income is reinforced by higher net tariff revenue, increasing Korean total expenditure and marginally reducing subsistence spending on agriculture. Together, these three factors imply a relatively strong positive domestic effect for agriculture than industry and a relatively strong negative foreign effect for industry as seen in Figure 6. Consequently, the magnitude of Korea's specialization in and the employment share of industry decline, and the employment share of agriculture increases throughout the sample period relative to the benchmark economy. Services' employment share barely changes. Its domestic expenditure share is reduced by higher tariff rates on traded goods, which lower its relative consumer price and expenditure share, but higher wage income offsets this.

The model's empirical performance, shown in Table 4, deteriorates relative to the benchmark model, with the RMSE for industry's employment share increasing by 42 percent and the total RMSE of the model by 9 percent. Only 50 percent of Korea's de-industrialization is captured by this counterfactual model, compared to 87.5 percent in the benchmark economy.

\section{Figure 6 goes here}

\subsubsection{The Role of Korea's Subsidy Policy}

Figure 7 depicts the effects of maintaining subsidy rates at their 1963 - and maximum - values in both sectors. As they are in the benchmark economy, subsidy rates are the same across sectors at all dates. Counterfactually high subsidies, as shown in the first line of Figure 7, reduce the price of Korean relative to OECD varieties confronted by OECD final good producers, increasing exports in both agriculture and industry. An incipient trade surplus results, necessitating higher Korean imports and/or an attenuation of higher exports to balance trade. The increase in OECD demand for Korean relative to OECD varieties results in an increase in relative Korean wages. Korean consumption expenditure and imports increase, while OECD consumption expenditure and imports decline. At the same time, higher relative Korean wages raise the producer prices of both Korean varieties relative to those in the OECD and engender expenditure switching towards OECD varieties, increasing Korean imports, and mitigating the increase in Korean exports induced by counterfactually higher subsidies to balance international trade.

Since subsidy rates are the same across sectors in both the benchmark economy and counterfactual experiment, they are not directly responsible for any change in the relative international competitiveness of industry and agriculture as maintaining 1963 tariff rates is. Nevertheless, transmission of higher subsidies and lower export prices to Korean export demand is amplified for 
industry because of lower OECD industrial than agricultural sector home bias, and Korea's industrial exports rise more than those of agriculture. In addition, the increase in Korean imports resulting from the higher Korean producer prices is larger in agriculture than industry on account of lower agricultural home bias. Increased Korean relative wage income, in conjunction with agriculture's relatively low income elasticity, somewhat offsets the increase in agriculture's net imports and industry's net exports, but is marginally weakened by the negative transfers due to maintaining high 1963 subsidies. Overall, industry's net exports and agriculture's net imports rise, agriculture suffers a disproportionately weak domestic and foreign effect compared to industry, and the employment share of industry rises and that of agriculture falls throughout the sample, relative to the benchmark economy as the bottom right panel of Figure 7 shows. Finally, negative net tariff income is sufficient to reduce services' employment share.

Table 4 shows that the counterfactual economy's fit declines relative to the benchmark model; the total RMSE of the model increases by more than 20 percent, and there are substantial increases in the RMSEs for both agriculture and industry. The speed and magnitude of industrialization is counterfactually high early in the sample. However, relative to the benchmark economy this experiment is better able to match the overall increase in industry's employment share, as the model generates about 84 percent of the increase in industry's employment share from 1963 to 2000 and 87.5 percent of Korea's de-industrialization. This result suggests that our subsidy measure may underestimate the degree of protection afforded industry by the policy, possibly because we use the same (industrial) subsidy rate in both sectors due to data limitations.

\section{Figure 7 goes here}

\subsection{The Role of Trade Policy Liberalization: "No Reform"}

Having analyzed the effects of keeping tariff and subsidy rates unchanged at their 1963 levels individually, we now evaluate the effects of combining the two experiments and maintaining both rates at their 1963 values as though Korea undertook no trade policy reform at all. As we have seen, the two policies have the same, positive effect for relative Korean wages, income, and producer prices through the aggregate trade balance adjustment mechanism. However, they have opposing effects on trade volumes and the pattern of trade; counterfactually high tariffs reduce trade and compress the pattern of international trade and specialization, while counterfactually high subsidies raise trade and accentuate this pattern. Therefore, when both tariff and subsidy rates remain at 1963 levels, the net impact for trade and structural change depends on the relative magnitudes of 
change in each policy instrument and on which policy instrument's transmission dominates. Figure 8 shows that the effects of maintaining counterfactually high 1963 subsidies dominate. Specifically, exports in both sectors increase in the counterfactual compared to the benchmark model, and more so in industry than in agriculture. This increase can only be due to the effect of higher (1963) subsidies. Because exports in both sectors increase, total imports must rise and/or the increase in exports must be attenuated to balance trade. Again, this is achieved by the shift in world demand in favor of Korean varieties, which increases Korean labor demand, wages, income, and producer prices relative to the OECD. Korean imports rise, and the increase in Korean exports produced by the relatively large effects of counterfactually high subsidies is mitigated, thus balancing trade.

On balance, the net exports of industry rise and those of agriculture fall relative to the benchmark economy, as we see in the 1963 subsidy rate experiment, but these effects are muted because tariffs are also counterfactually high. Industry's employment share rises somewhat, and that of agriculture falls, from 1964 onwards. Services' domestic consumption expenditure share is essentially unaffected; a small decline in services' relative consumer price because of (generally) higher tariffs on traded goods tends to decrease services' domestic consumption expenditure share, but higher Korean income increases it at the expense of agriculture due to non-homothetic preferences. Services' employment share is marginally reduced, due to a small negative net tariff income transfer from the government, relative to the benchmark economy, as higher subsidies raise expenditure slightly more than higher tariffs raise tariff income.

While the summary statistics of the counterfactual are not significantly different from those of the benchmark model, these statistics do not reflect the differences we observe in the model's implied pattern of industrialization relative to the data, and especially the counterfactually high level of industrial employment in the first half of the sample. This model estimates just 48 percent, of the 25 percentage point increase in industry's employment share after 1963, and about 62.5 percent, of its 8 percentage point subsequent maximum decline.

Overall, these three counterfactual experiments demonstrate that Korean tariff reform after 1963 promoted the international competitiveness and employment share of industry, but this was more than offset by Korean subsidy reform which disproportionately reduced the competitiveness and employment share of the sector. Korean industrialization would have been greater and more rapid had she not undertaken the pattern of simultaneous reform of both instruments observed in the benchmark economy and data, and especially if she had maintained high export subsidies 
and reformed only tariffs after 1963. Although reforming one instrument at a time has powerful consequences for international trade and structural change, Korea's actual trade reform that is simulated by the benchmark economy has muted consequences because the effects of tariff and subsidy reform offset each other.

\section{Figure 8 goes here}

\subsection{Immediate Full Liberalization}

In the final experiment, we assume that Korea immediately and completely liberalized her international trade in 1963. Specifically, we set to zero all Korean tariffs on imports and all subsidies to exports in 1963, and hold them there throughout the sample. This experiment represents an upper bound on trade reform in Korea, relative to the lower bound of the previous trade policy experiment. However this experiment does not represent a free trade regime. OECD tariffs remain in the model, and the calibration of the Armington aggregator weights remains unchanged, reflecting all real trade costs confronted by an open Korean economy not measured by our tariff and subsidy time series. The effects of this experiment are shown in Figure 9.

The relative price effect of zero subsidies reduces OECD demand for Korean exports, and that of zero tariffs raises Korean demand for OECD imports, and a large incipient trade deficit results. Trade must be balanced and this is accomplished via the sharp decline in world demand for Korean relative to OECD varieties produced by the policy, reducing Korean labor demand, wages, income, and producer prices relative to the OECD. Here, we find the increase in industry's relative competitiveness caused by the instantaneous reduction in tariffs from 60 percent to zero actually dominates the instantaneous reduction in industry's competitiveness caused by reducing subsidies from 40 percent to zero. We find the pattern of structural change is surprisingly similar to that of the "no reform" economy; industrialization is stronger relative to the benchmark model. This similarity arises because the evolution of relative variety prices across sectors are almost identical in the two counterfactuals. Whether Korean tariffs and subsidies are all held constant at zero or at 1963 values - which are identical for subsidies across sectors and very similar for tariffs- international labor productivity growth differentials across sectors and sectoral differences in OECD tariffs solely determine this evolution. Finally, exports, imports, and total trade increase dramatically relative to the benchmark and the "no reform" economies, as seen in the third and fourth rows of Figure 9) .

Table 4 shows that the performance of the model deteriorates relative to that of the bench- 
mark economy as measured by the RMSE, while the correlation statistics are roughly the same.

\section{Figure 9 goes here}

\section{Conclusion}

A quantitative open economy model of structural change featuring non-homothetic preferences, Armington trade, and a novel representation of trade policy by sequences of proportional tariffs and subsidies, implies Korean sectoral employment allocations, and bilateral value added trade volumes with the OECD, which are qualitatively and quantitatively similar to those in the data. By contrast, a variant of the model counterfactually closed to international trade generates neither the industrialization nor de-industrialization that characterized the Korean economy between 1963 and 2000. Two forces generate more realistic structural change in the open economy.

First, income is initially lower in the open than in the closed economy model. Consequently, there are stronger income effects due to the subsistence consumption requirement - which reallocate labor resources out of agriculture early in the sample, promoting industrialization, and weakening income effects late in the sample as Korean GDP grows which contribute to de-industrialization. Second, productivity and policy driven international relative price changes, interacting with the sectoral pattern of home bias, generate expenditure switching which slants the pattern of international trade and specialization in favor of Korean industry in the first half of the sample, and against it subsequently.

Despite their contribution to the model's ability to generate de-industrialization, even large trade policy changes do not penetrate the model's implied pattern of trade and specialization per se, which favors Korea's industrial sector and the OECD agricultural sector at every date. Consequently, Korea's trade reform had a limited impact on structural change. The pattern of trade is, instead, largely attributable to relatively low home bias in the OECD industrial sector and in Korean agriculture, reinforced by powerful income effects in Korea relative to the OECD. The relatively small effects of tariff and subsidy rate changes for the pattern of trade and specialization partly result from the restriction that aggregate trade be balanced. The policy reforms we study, by changing the prices of Korean relative to OECD varieties within at least one sector, initiate aggregate net trade between the two countries. This imbalance is eliminated by endogenous adjustments in factor costs, which change producer prices in both traded sectors proportionally and in the opposing direction to that initiated by the exogenous policy change. Any inter-sector trade or shift in international specialization due to policy changes is consequently moderated. 
Relaxing the balanced trade assumption, allowing Korea to fund trade deficits with credit and lend trade surpluses, would increase the sensitivity to policy changes - and other sources of aggregate net trade - of total and sectoral net exports, and of sectoral employment shares. Nonetheless, Korea's simultaneous tariff and subsidy reforms had opposing effects for the relative competitiveness of sectors, muting the structural change outcomes of her international trade policies. Additionally, the common export subsidy series that we input for both sectors due to data limitations may limit the sectoral reallocations associated with reform of this policy instrument. Finally, to the extent that endogenous labor productivity improvements result from tariff and subsidy reform, we underestimate the role of trade liberalization in effecting structural change. Beyond the scope of the current paper, we leave investigation of this issue for future research.

\section{References}

Anderson, J. E. and Wincoop, E. v. (2003), 'Gravity with Gravitas: A Solution to the Border Puzzle', American Economic Review 93(1), 170-192.

Backus, D. K., Kehoe, P. J. and Kydland, F. E. (1992), 'International Real Business Cycles', Journal of Political Economy 100(4), 745-75.

Backus, D. K., Kehoe, P. J. and Kydland, F. E. (1994), 'Dynamics pf the Trade Balance and the Terms of Trade:The J-Curve?', American Economic Review 84(1), 84-103.

Collins, S. M. and Park, W.-A. (1989a), 'Developing Country Debt and Economic Performance, Volume 3: Country Studies - Indonesia, Korea, Philippines, Turkey', ed. Jeffrey D. Sachs and Susan M. Collins, University of Chicago Press pp. 121-140.

Collins, S. M. and Park, W.-A. (1989b), External Debt and Macroeconomic Performance in South Korea.

Connolly, M. and Yi, K.-M. (2015), 'How Much of South Korea's Growth Miracle Can Be Explained by Trade Policy?', American Economic Journal: Macroeconomics 7(4), 188-221.

Duarte, M. and Restuccia, D. (2010), 'The Role of the Structural Transformation in Aggregate Productivity', The Quarterly Journal of Economics 125 (1), 129-173.

Eaton, J. and Kortum, S. S. (2002), 'Technology, Geography, and Trade', Econometrica 70(5), 1741-1779.

Giri, R. (2012), 'Local Costs of Distribution, International Trade Costs and Micro Evidence on the Law of One Price', Journal of International Economics 86(1), 82-100.

Herrendorf, B., Rogerson, R. and Valentinyi, A. (2013), 'Two Perspectives on Preferences and 
Structural Transformation', American Economic Review 103.

Herrendorf, B., Rogerson, R. and Valentinyi, A. (2014), 'Growth and Structural Transformation', Handbook of Economic Growth .

Johnson, R. C. and Noguera, G. (2014), 'A Portrait of Trade in Value Added over Four Decades', Working Paper .

Kim, N. (1996), Measuring the costs of visible protection in Korea, Peterson Institute for International Economics.

Lee, J.-W. (1995), 'Government Intervention and Productivity Growth in Korean Manufacturing', NBER Working Paper Series (5060).

Nam, C. H. (1980), Trade and Industrial Policies, and the Structure of Protection in Korea, Korea Development Institute.

Nam, C. H. (1995), The Role of Trade and Exchange Rate Policy in Koreas Growth, in T. Ito and A. O. Krueger, eds, 'Growth Theories in Light of the East Asian Experience. NBER East Asian Seminar on Economics, Series 4', University of Chicago Press.

Ruhl, K. (2008), 'The International Elasticity Puzzle', Working Paper .

Simonovska, I. and Waugh, M. E. (2014), 'The Elasticity of Trade: Estimates and Evidence', Journal of International Economics 92(1), 34-50.

Sposi, M. (2014), 'Evolving Comparative Advantage, Structural Change, and the Composition of Trade', Working Paper .

Teignier, M. (2014), 'The Role of Trade in Structural Transformation', Working Paper .

Uy, T., Yi, K.-M. and Zhang, J. (2013), 'Structural Change in an Open Economy', Journal of Monetary Economics 60(6), 667-682.

Waugh, M. (2010), 'International Trade and Income Differences', American Economic Review 100(5), 2093-2124.

Yi, K.-M. (2003), 'Can Vertical Specialization Explain the Growth of World Trade?', Journal of Political Economy 111(1), 52-102.

Zimmermann, C. (1997), 'International Real Business Cycles among Heterogeneous Countries', European Economic Review 41(1), 349-5. 


\section{A Appendix - Tables}

Table 1: Average Tariff Rates (in \%)

\begin{tabular}{|c|c|c|c|c|}
\hline \multirow[b]{2}{*}{ Year } & \multicolumn{2}{|c|}{ Imposed by Korea } & \multicolumn{2}{|c|}{ Imposed by OECD } \\
\hline & Industry & Agriculture & Industry & Agriculture \\
\hline 1963 & 60.72 & 66.55 & 12.8 & 4.2 \\
\hline 1964 & 60.72 & 66.55 & 12.5 & 4.1 \\
\hline 1965 & 60.72 & 66.55 & 12.1 & 4.1 \\
\hline 1966 & 60.72 & 66.55 & 11.8 & 4.1 \\
\hline 1967 & 60.72 & 66.55 & 11.5 & 4 \\
\hline 1968 & 70.6 & 36.5 & 11.3 & 4 \\
\hline 1969 & 70.6 & 36.5 & 11 & 4 \\
\hline 1970 & 70.6 & 36.5 & 10.7 & 3.9 \\
\hline 1971 & 70.6 & 36.5 & 10.4 & 3.9 \\
\hline 1972 & 70.6 & 36.5 & 10.2 & 3.9 \\
\hline 1973 & 67.78 & 32.44 & 9.9 & 3.9 \\
\hline 1974 & 67.78 & 32.44 & 9.7 & 3.8 \\
\hline 1975 & 67.78 & 32.44 & 9.4 & 3.8 \\
\hline 1976 & 67.78 & 32.44 & 9.2 & 3.8 \\
\hline 1977 & 67.78 & 32.44 & 8.9 & 3.7 \\
\hline 1978 & 67.78 & 32.44 & 8.7 & 3.7 \\
\hline 1979 & 49.42 & 29.48 & 8.5 & 3.7 \\
\hline 1980 & 49.42 & 29.48 & 8.3 & 3.7 \\
\hline 1981 & 49.42 & 29.48 & 8.1 & 3.6 \\
\hline 1982 & 49.42 & 29.48 & 7.9 & 3.6 \\
\hline 1983 & 22.6 & 31.4 & 7.7 & 3.6 \\
\hline 1984 & 20.6 & 29.6 & 7.5 & 3.5 \\
\hline 1985 & 20.3 & 28.8 & 7.3 & 3.5 \\
\hline 1986 & 18.7 & 27.1 & 7.1 & 3.5 \\
\hline 1987 & 18.2 & 26.4 & 6.9 & 3.5 \\
\hline 1988 & 16.9 & 25.2 & 6.8 & 3.4 \\
\hline 1989 & 11.2 & 20.6 & 6.6 & 3.4 \\
\hline 1990 & 9.7 & 19.9 & 6.6 & 3.4 \\
\hline 1991 & 9.7 & 19.9 & 6.7 & 3 \\
\hline 1992 & 8.4 & 18.5 & 6.6 & 3.4 \\
\hline 1993 & 7.1 & 17.8 & 6.7 & 3.2 \\
\hline 1994 & 6.2 & 16.6 & 6.7 & 3.2 \\
\hline 1995 & 6.2 & 16.6 & 5.9 & 3.2 \\
\hline 1996 & 6.2 & 16.6 & 5.6 & 3 \\
\hline 1997 & 6.2 & 16.6 & 5.3 & 3 \\
\hline 1998 & 6.2 & 16.6 & 4.7 & 3.1 \\
\hline 1999 & 6.2 & 16.6 & 4.3 & 3.8 \\
\hline 2000 & 6.2 & 16.6 & 4.2 & 3.6 \\
\hline
\end{tabular}


Table 2: Export Subsidies, 1958-85 (annual averages)

\begin{tabular}{|c|c|c|c|c|c|c|c|c|c|c|c|c|}
\hline \multirow[b]{3}{*}{ Year } & \multicolumn{3}{|c|}{ I } & \multicolumn{6}{|c|}{ Won Subsidies Per U.S. Dollar of Export } & \multicolumn{3}{|c|}{ Ratio to Exchange Rate (\%) } \\
\hline & $\begin{array}{l}\text { Official Exchange } \\
\text { Rate (won/dollar) }\end{array}$ & $\begin{array}{r}\text { Direct Cash } \\
\text { Subsidies }\end{array}$ & $\begin{array}{r}\text { Export Dollar } \\
\text { Premium }\end{array}$ & $\begin{array}{l}\text { Direct Tax } \\
\text { Reduction }\end{array}$ & $\begin{array}{r}\text { Interest Rate } \\
\text { Preference }\end{array}$ & $\begin{array}{r}\text { Net } \\
\text { Subsidies }\end{array}$ & $\begin{array}{r}\text { Indirect Tax } \\
\text { Exemptions }\end{array}$ & $\begin{array}{r}\text { Tariff } \\
\text { Exemptions }\end{array}$ & $\begin{array}{r}\text { Gross } \\
\text { Subsidies }\end{array}$ & $\begin{array}{l}\text { Sub } \\
\text { Net }\end{array}$ & dies Gross & $\begin{array}{l}\text { Gross Subsidy minus } \\
\text { Tariff Exemptions }\end{array}$ \\
\hline & (1) & (2) & (3) & (4) & (5) & $(6=2+3+4+5)$ & (7) & (8) & $(9=6+7+8)$ & $\mid(10=6 / 1)$ & $(11=9 / 1)$ & $(11=(9-8) / 1)$ \\
\hline 1958 & 50 & 0 & 64 & 0 & 1.2 & 65.2 & 0 & 0 & 65.2 & 130.4 & 130.4 & 130.4 \\
\hline 1959 & 50 & 0 & 84.7 & 0 & 1.3 & 86 & 0 & 0 & 86 & 172 & 172 & 172.0 \\
\hline 1960 & 62.5 & 0 & 83.9 & 0 & 1.2 & 85.1 & 0 & 0 & 85.1 & 136.2 & 136.2 & 136.2 \\
\hline 1961 & 127.5 & 7.5 & 14.6 & 0 & 1 & 23.1 & 0 & 0 & 23.1 & 18.1 & 18.1 & 18.1 \\
\hline 1962 & 130 & 10.3 & 0 & 0.6 & 0.9 & 11.8 & 5.1 & 4.7 & 21.6 & 9.1 & 16.6 & 13.0 \\
\hline 1963 & 130 & 4.1 & 39.8 & 0.8 & 2.9 & 47.6 & 5.3 & 6.6 & 59.5 & 36.6 & 45.8 & 40.7 \\
\hline 1964 & 214.3 & 2.9 & 39.7 & 0.7 & 6 & 49.3 & 7.6 & 10.1 & 67 & 23 & 31.3 & 26.6 \\
\hline 1965 & 265.4 & 0 & 0 & 2.3 & 7.6 & 9.9 & 13.9 & 15.4 & 39.2 & 3.7 & 14.8 & 9.0 \\
\hline 1966 & 271.3 & 0 & 0 & 2.3 & 10.3 & 12.6 & 17.8 & 21.3 & 51.7 & 4.6 & 19.1 & 11.2 \\
\hline 1967 & 270.7 & 0 & 0 & 5.2 & 14.7 & 19.9 & 17.8 & 24.6 & 62.3 & 7.4 & 23 & 13.9 \\
\hline 1968 & 276.6 & 0 & 0 & 3 & 15.2 & 18.2 & 19.9 & 39.6 & 77.7 & 6.6 & 28.1 & 13.8 \\
\hline 1969 & 288.2 & 0 & 0 & 3.7 & 14.7 & 18.4 & 27.4 & 34.3 & 80.1 & 6.4 & 27.8 & 15.9 \\
\hline 1970 & 310.7 & 0 & 0 & 3.5 & 17.3 & 20.8 & 27 & 40.4 & 88.2 & 6.7 & 28.4 & 15.4 \\
\hline 1971 & 347.7 & 0 & 0 & 4.8 & 18.1 & 22.9 & 32.2 & 48 & 103.1 & 6.6 & 29.7 & 15.8 \\
\hline 1972 & 391.8 & 0 & 0 & 1.9 & 10.5 & 12.4 & 26.4 & 66.3 & 105.1 & 3.2 & 26.8 & 9.9 \\
\hline 1973 & 398.3 & 0 & 0 & 1.4 & 7.4 & 8.8 & 21 & 64.4 & 94.2 & 2.2 & 23.7 & 7.5 \\
\hline 1974 & 407 & 0 & 0 & 0 & 8.6 & 8.6 & 22.5 & 55.1 & 86.2 & 2.1 & 21.2 & 7.6 \\
\hline 1975 & 484 & 0 & 0 & 0 & 12.9 & 12.9 & 33.8 & 34.3 & 81 & 2.7 & 16.7 & 9.6 \\
\hline 1976 & 484 & 0 & 0 & 0 & 12.3 & 12.3 & 33.6 & 35.9 & 81.8 & 2.5 & 16.9 & 9.5 \\
\hline 1977 & 484 & 0 & 0 & 0 & 9.4 & 9.4 & 53.1 & 30.6 & 93.1 & 1.9 & 19.2 & 12.9 \\
\hline 1978 & 484 & 0 & 0 & 0 & 11 & 11 & 53.6 & 30 & 94.6 & 2.3 & 19.5 & 13.3 \\
\hline 1979 & 484 & 0 & 0 & 0 & 11 & 11 & 56.6 & 30.3 & 97.9 & 2.3 & 20.2 & 14.0 \\
\hline 1980 & 618.5 & 0 & 0 & 0 & 20.6 & 20.6 & 74.6 & 36.4 & 131.6 & 3.3 & 21.3 & 15.4 \\
\hline 1981 & 686 & 0 & 0 & 0 & 15 & 15 & n.a. & n.a. & n.a. & 2.2 & n.a. & n.a. \\
\hline 1982 & 737.7 & 0 & 0 & 0 & 3 & 3 & n.a. & n.a. & n.a. & 0.4 & n.a. & n.a. \\
\hline 1983 & 781.2 & 0 & 0 & 0 & 0 & 0 & n.a. & n.a. & n.a. & 0 & n.a. & n.a. \\
\hline 1984 & 807.1 & 0 & 0 & 0 & 0 & 0 & n.a. & n.a. & n.a. & 0 & n.a. & n.a. \\
\hline 1985 & 871.7 & 0 & 0 & 0 & 0 & 0 & n.a. & n.a. & n.a. & 0 & n.a. & n.a. \\
\hline
\end{tabular}


Table 3: Calibrated Values of Armington Weights

\begin{tabular}{rr}
\hline$\mu_{i}^{k}$ & Value \\
\hline$\mu_{K O R}^{A}$ & 0.36 \\
$\mu_{K O R}^{I}$ & 0.41 \\
$\mu_{O E C D}^{A}$ & 0.84 \\
$\mu_{O E C D}^{I}$ & 0.77 \\
\hline
\end{tabular}

Table 4: Model Performance Measures for South Korea: Benchmark versus Counterfactuals

\begin{tabular}{|c|c|c|c|c|}
\hline \multicolumn{5}{|c|}{ Benchmark Open Economy - $\bar{A}=544.73$} \\
\hline Performance Measure & Agriculture & Industry & Services & Total \\
\hline Sum of Squared Errors & 0.0773 & 0.1375 & 0.2984 & 0.5133 \\
\hline Root Mean Squared Error & 0.0451 & 0.0602 & 0.0886 & 0.1162 \\
\hline Correlation Coefficient & 0.9867 & 0.815 & 0.9488 & \\
\hline \multicolumn{5}{|c|}{ Closed Economy $-\mu_{i}^{k}=1 \forall k, i$} \\
\hline Performance Measure & Agriculture & Industry & Services & Total \\
\hline Sum of Squared Errors & 1.9598 & 0.4578 & 3.0371 & 5.4547 \\
\hline Root Mean Squared Error & 0.2271 & 0.1098 & 0.2827 & 0.3789 \\
\hline Correlation Coefficient & 0.9909 & 0.8706 & 0.9646 & \\
\hline \multicolumn{5}{|c|}{ Tariffs held at 1963 levels } \\
\hline Performance Measure & Agriculture & Industry & Services & Total \\
\hline Sum of Squared Errors & 0.0173 & 0.2785 & 0.3141 & 0.6099 \\
\hline Root Mean Squared Error & 0.0214 & 0.0856 & 0.0909 & 0.1267 \\
\hline Correlation Coefficient & 0.9926 & 0.8285 & 0.9507 & \\
\hline \multicolumn{5}{|c|}{ Subsidies held at 1963 levels } \\
\hline Performance Measure & Agriculture & Industry & Services & Total \\
\hline Sum of Squared Errors & 0.4075 & 0.2212 & 0.1145 & 0.7432 \\
\hline Root Mean Squared Error & 0.1036 & 0.0763 & 0.0549 & 0.1398 \\
\hline Correlation Coefficient & 0.9671 & 0.7891 & 0.9532 & \\
\hline \multicolumn{5}{|c|}{ Tariffs and Subsidies held at 1963 levels } \\
\hline Performance Measure & Agriculture & Industry & Services & Total \\
\hline Sum of Squared Errors & 0.1745 & 0.1004 & 0.247 & 0.5219 \\
\hline Root Mean Squared Error & 0.0678 & 0.0514 & 0.0806 & 0.1172 \\
\hline Correlation Coefficient & 0.9832 & 0.7862 & 0.9525 & \\
\hline \multicolumn{5}{|c|}{ Zero Tariffs and Subsidies } \\
\hline Performance Measure & Agriculture & Industry & Services & Total \\
\hline Sum of Squared Errors & 0.1723 & 0.0996 & 0.2566 & 0.5285 \\
\hline Root Mean Squared Error & 0.0673 & 0.0512 & 0.0822 & 0.1179 \\
\hline Correlation Coefficient & 0.9836 & 0.7922 & 0.9523 & \\
\hline
\end{tabular}


B Appendix - Figures
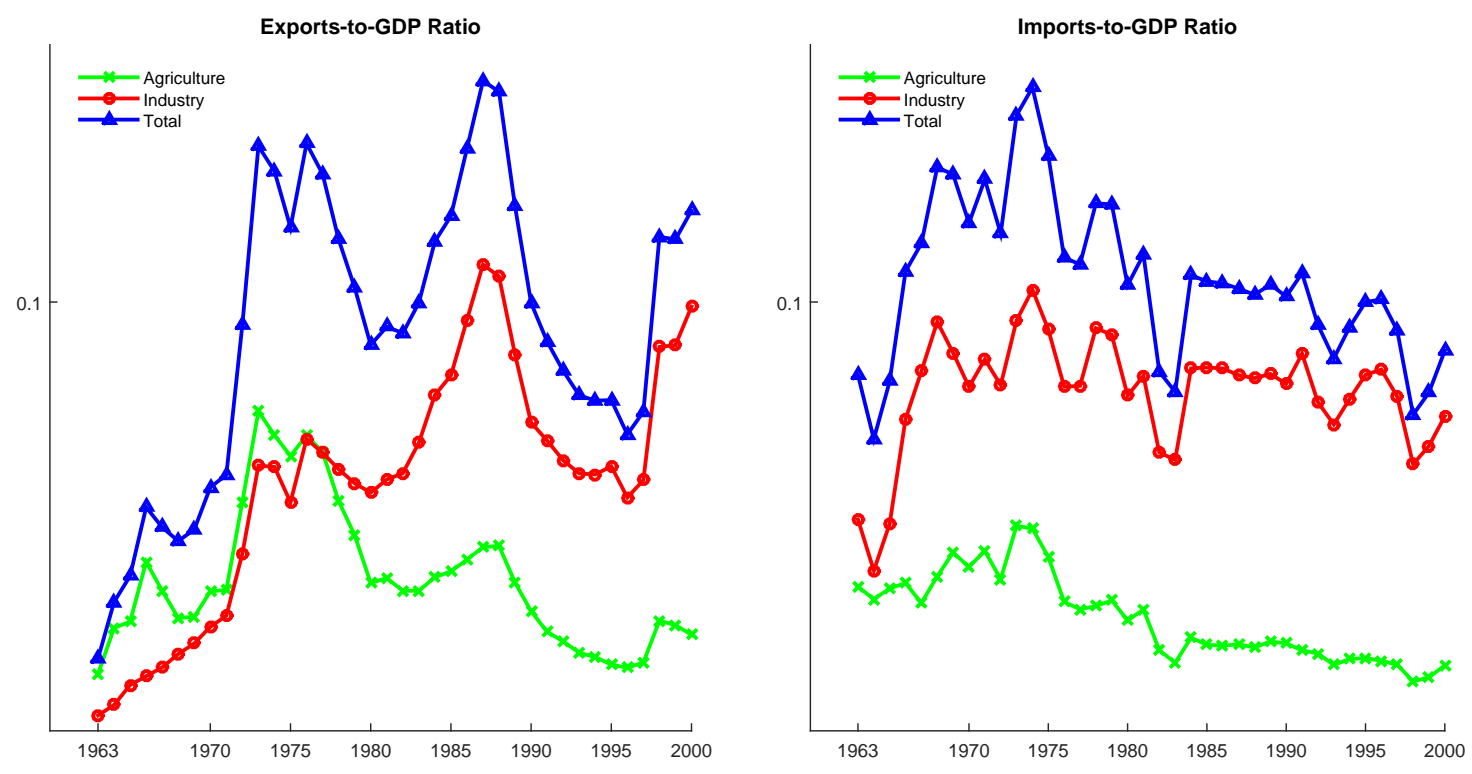

Figure 1: Evolution of Value Added Trade in South Korea (with OECD), 1963-2000
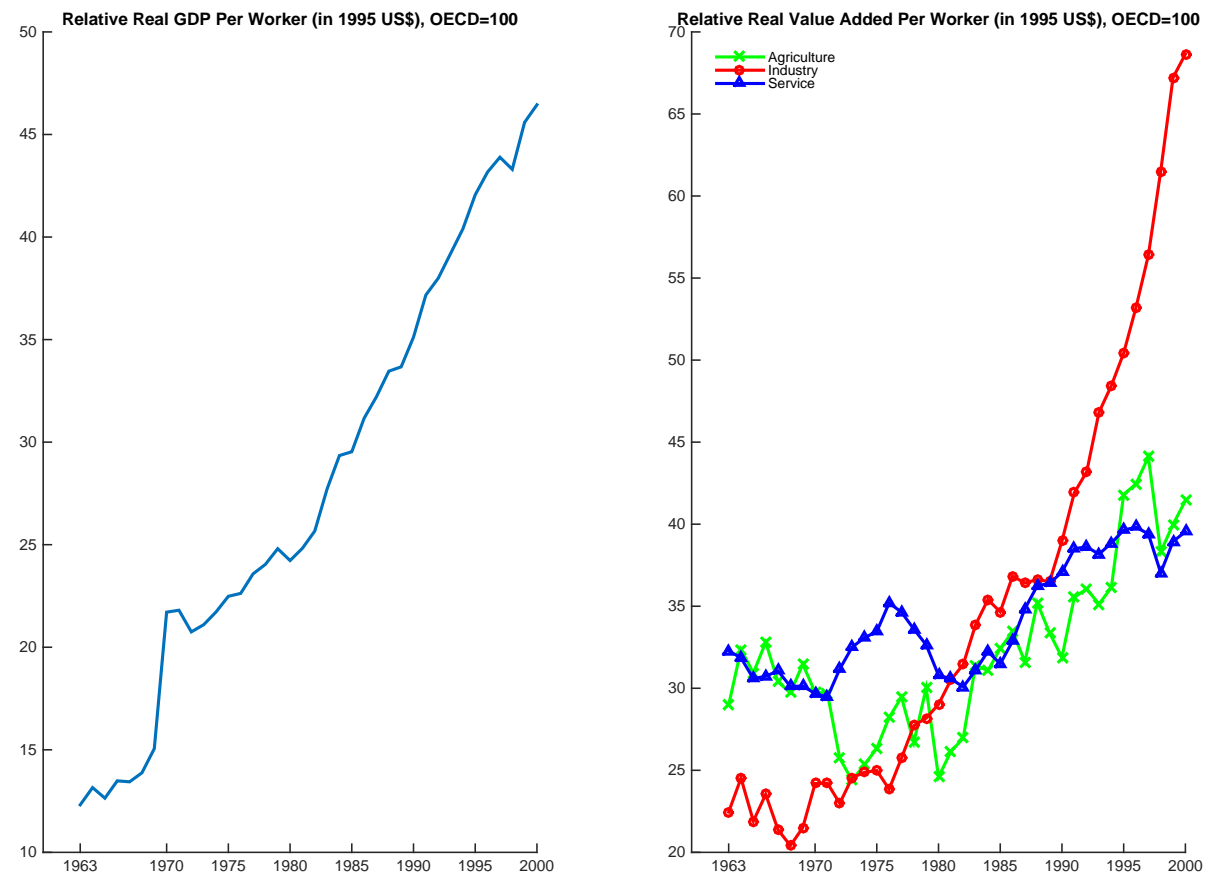

Figure 2: GDP Per Worker and Labor Productivity in South Korea (relative to OECD), 1963-2000 

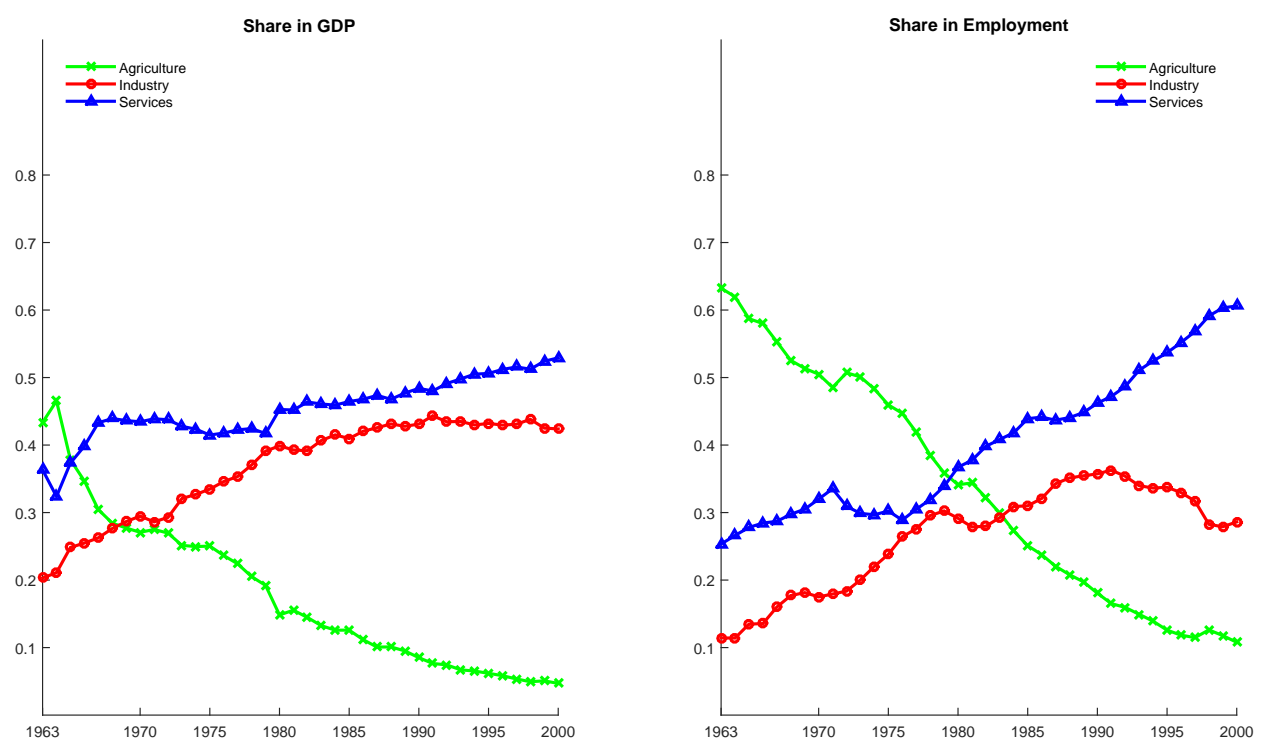

Figure 3: Structural Change in South Korea, 1963-2000 

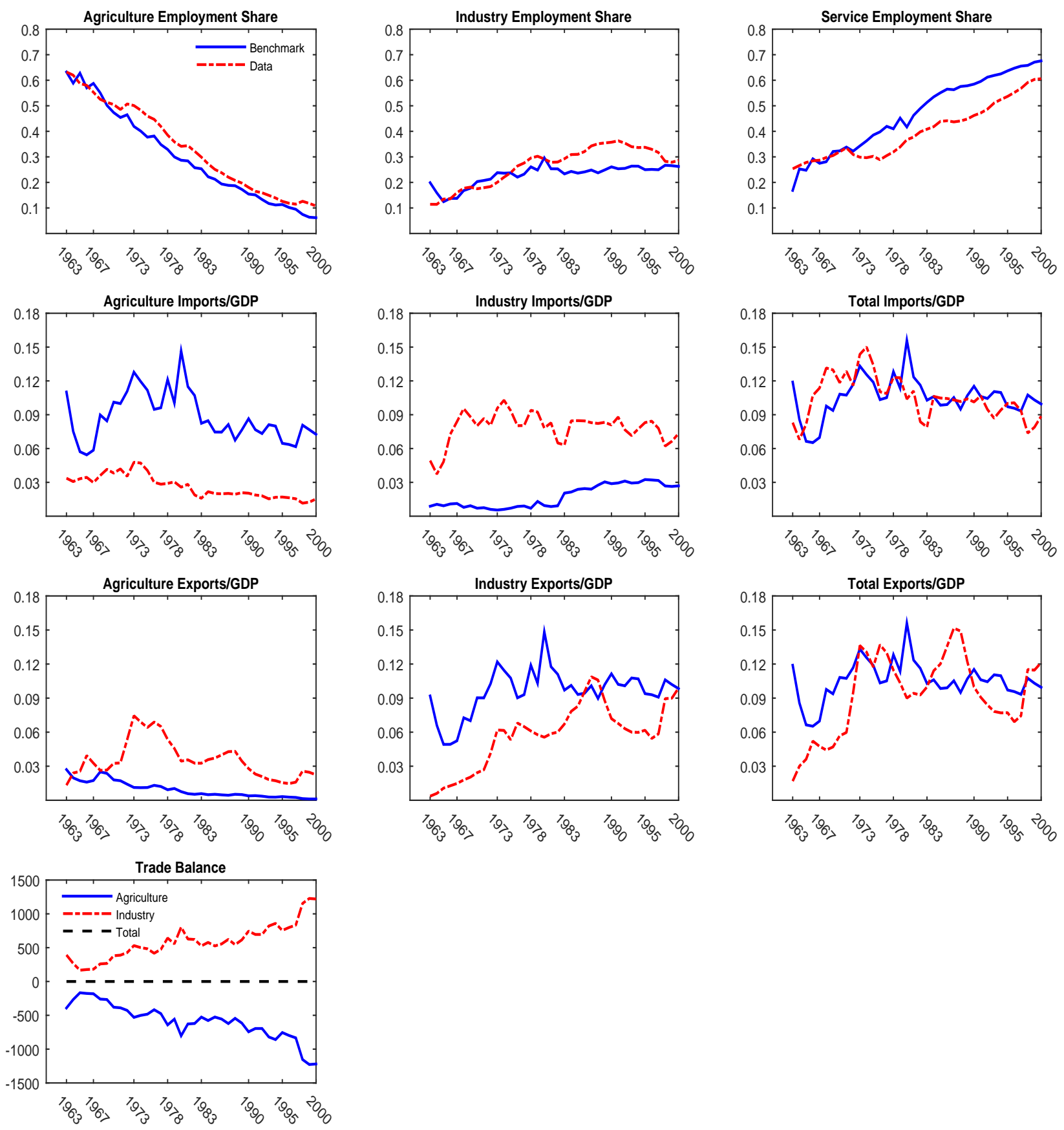

Figure 4: Benchmark Model versus Data 

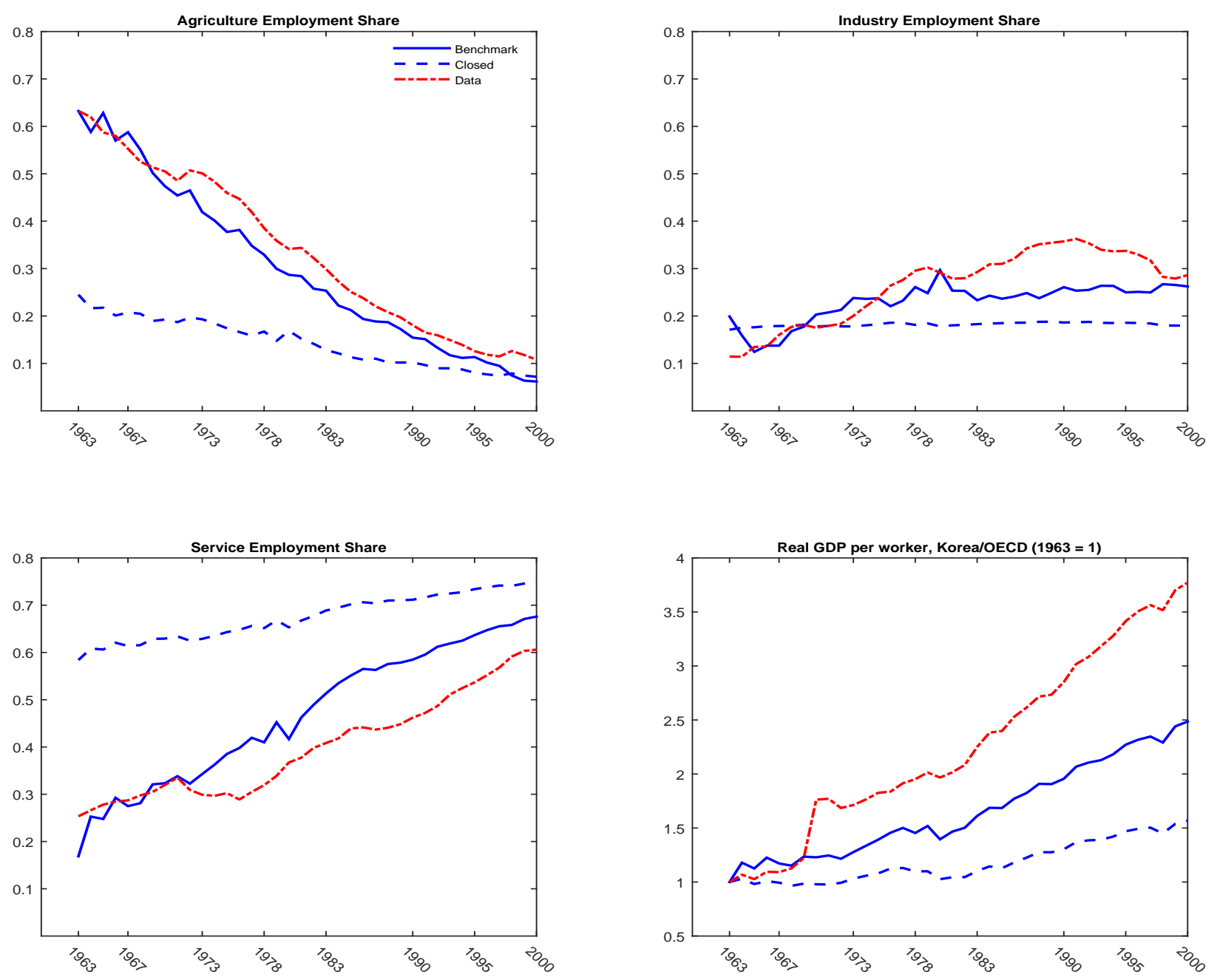

Figure 5: Employment Shares by Sector: Closed vs Benchmark vs Data 

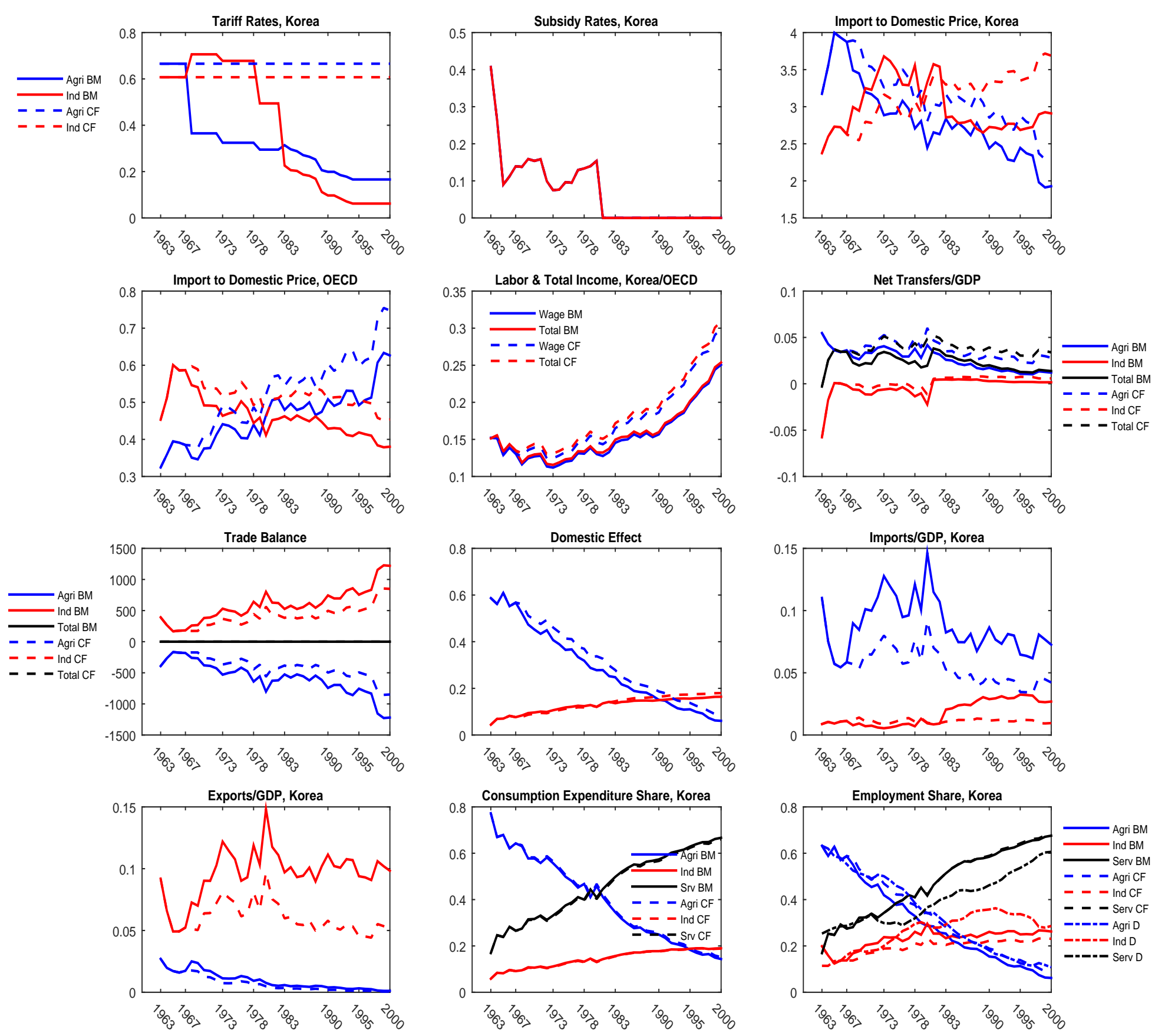

Figure 6: No Change in Tariff Policy in South Korea

Notes: BM denotes Benchmark, CF denotes Counterfactual, and D denotes Data.

Agri denotes Agriculture, Ind denotes Industry, and Serv denotes Service. 

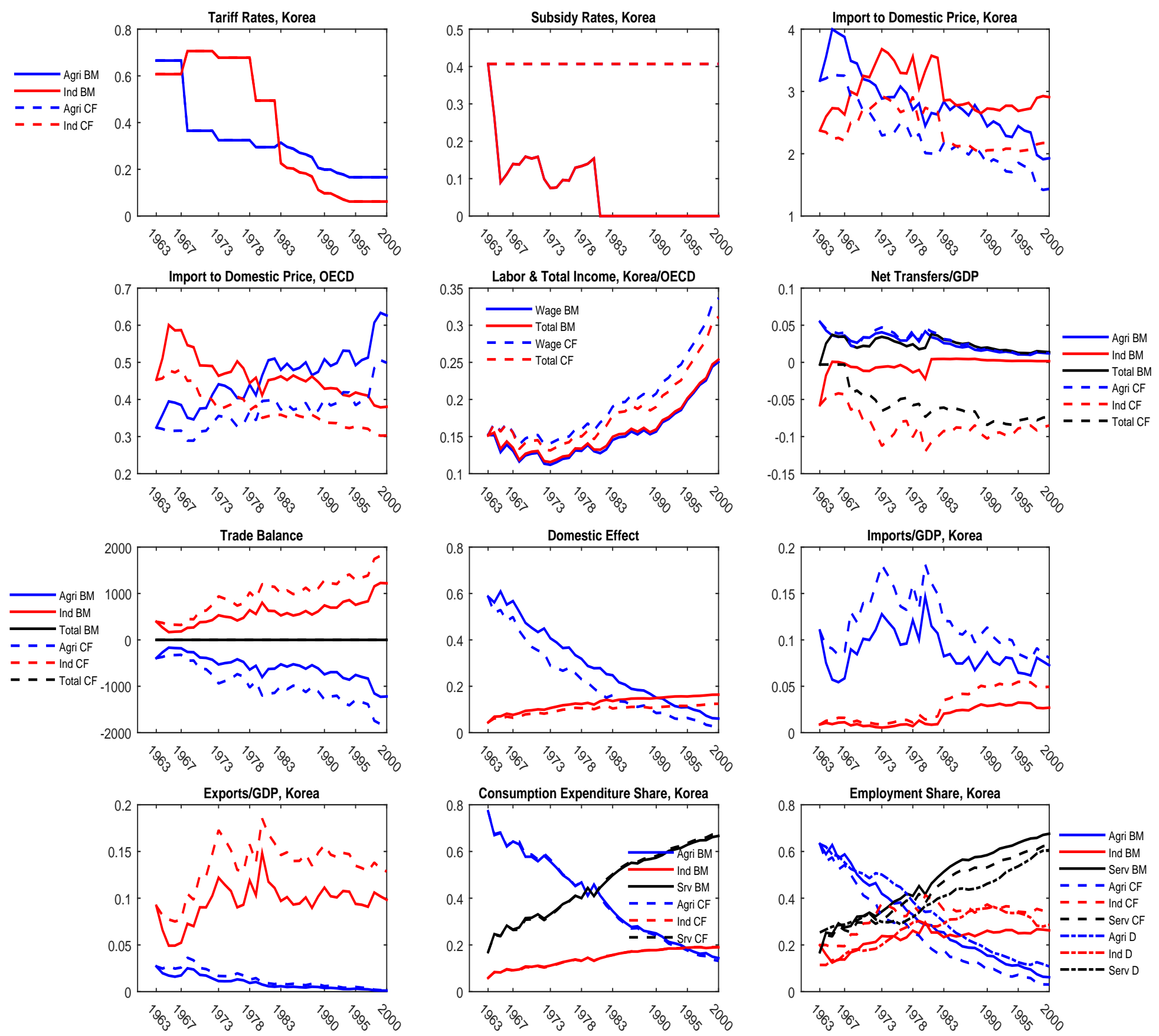

Figure 7: No Change in Subsidy Policy in South Korea

Notes: BM denotes Benchmark, CF denotes Counterfactual, and D denotes Data.

Agri denotes Agriculture, Ind denotes Industry, and Serv denotes Service. 

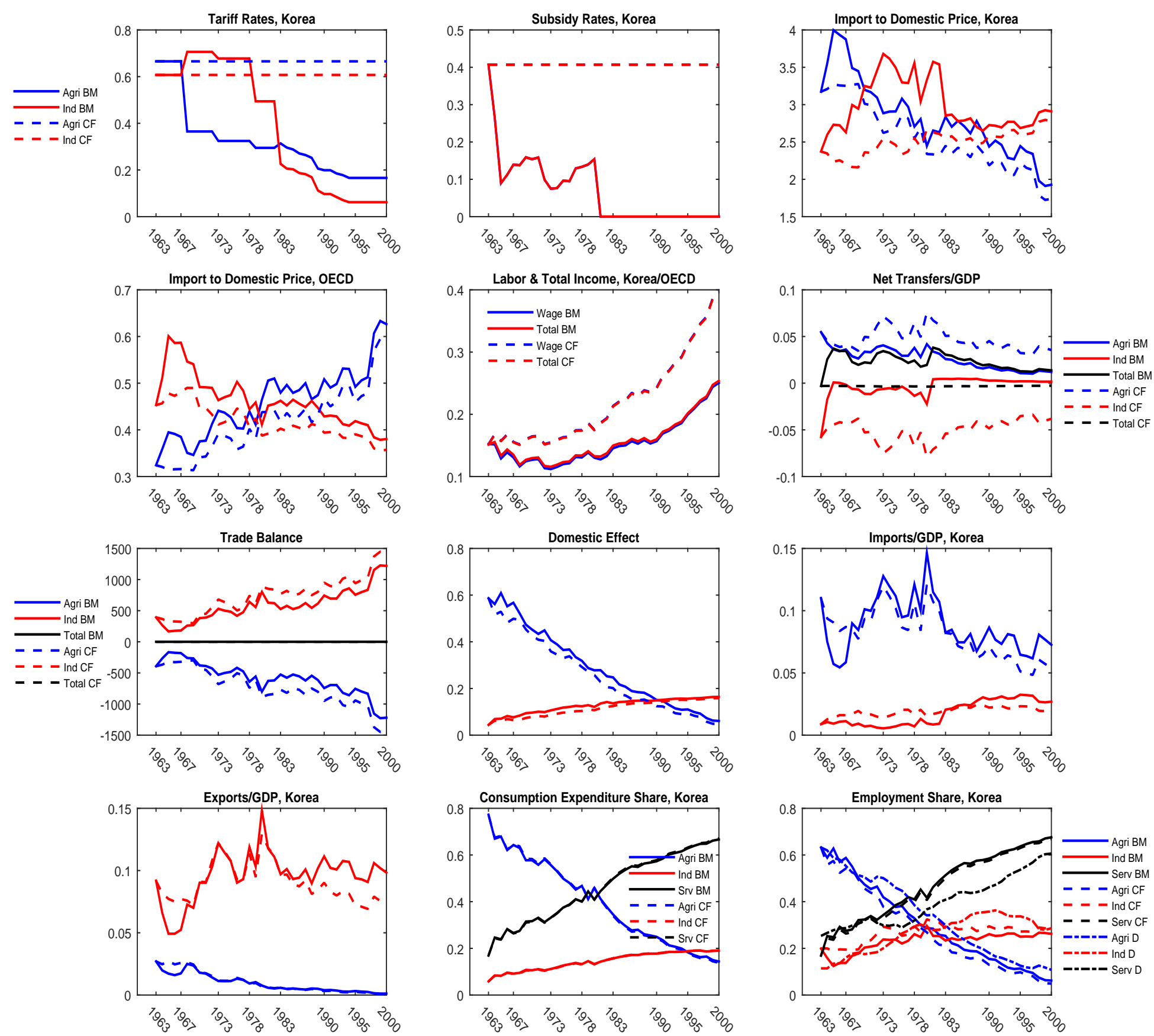

Figure 8: No Change in Tariff and Subsidy Policies in South Korea

Notes: BM denotes Benchmark, CF denotes Counterfactual, and D denotes Data.

Agri denotes Agriculture, Ind denotes Industry, and Serv denotes Service. 

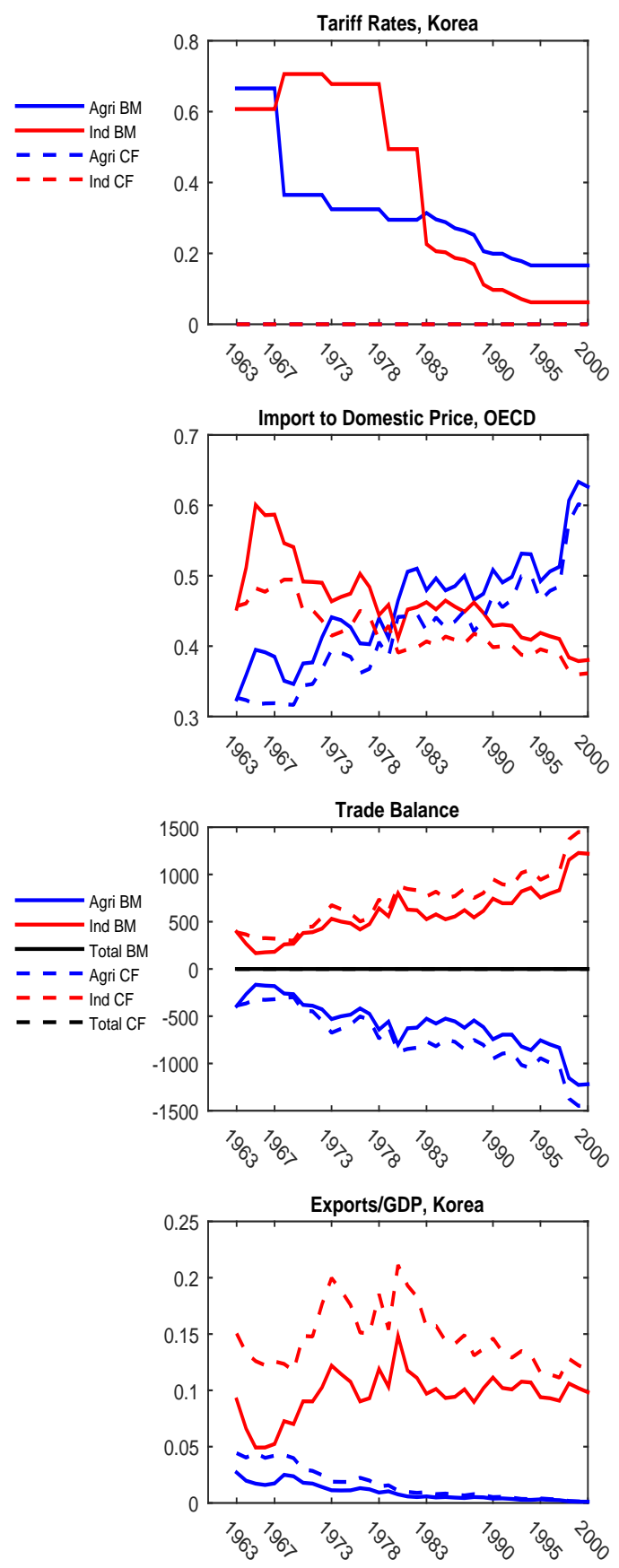
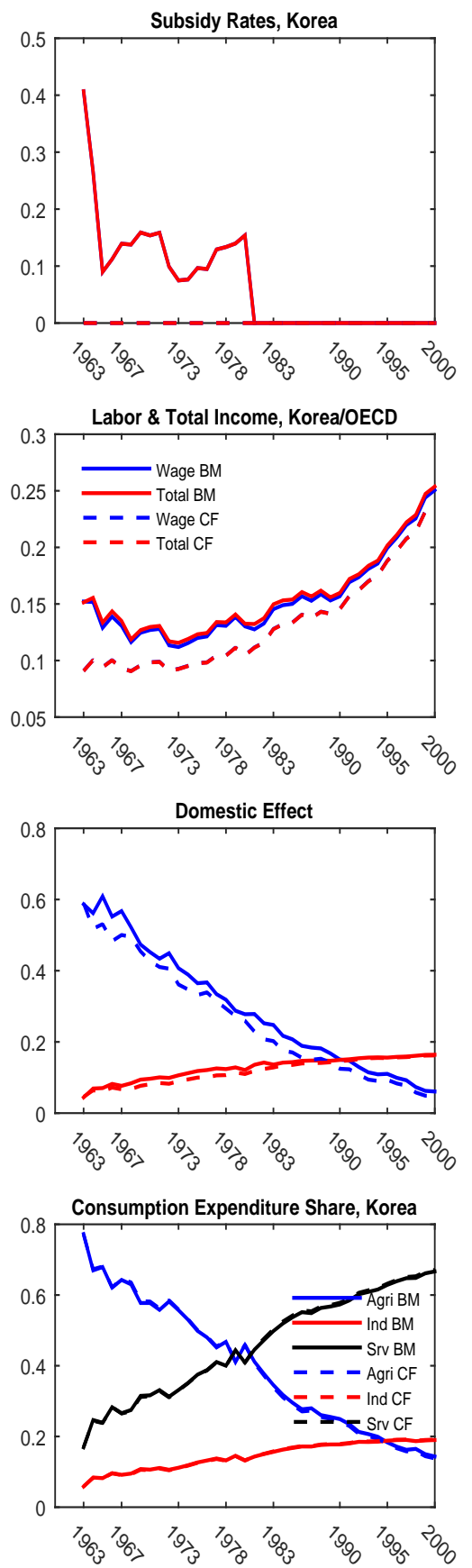
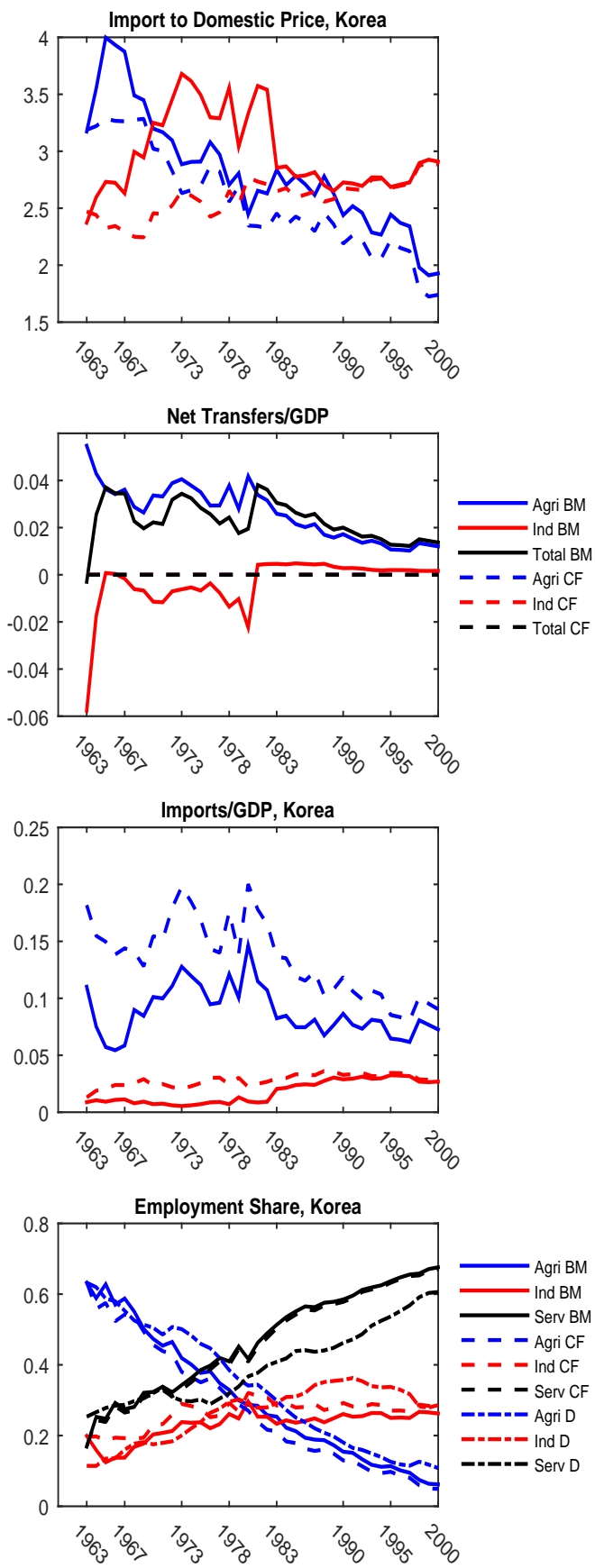

Figure 9: Full and Immediate Liberalization in South Korea

Notes: BM denotes Benchmark, CF denotes Counterfactual, and D denotes Data. Agri denotes Agriculture, Ind denotes Industry, and Serv denotes Service. 